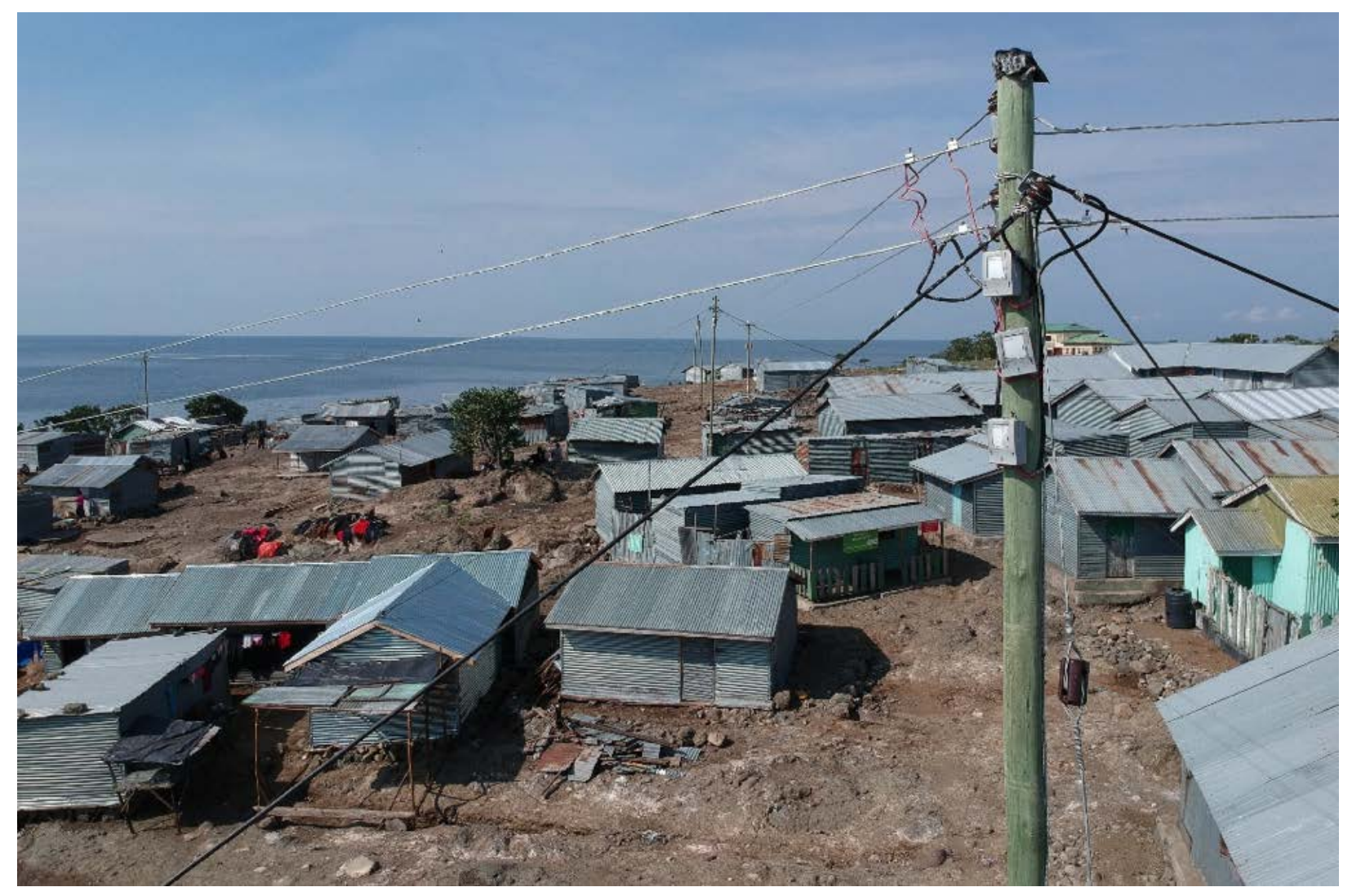

\title{
PERFORMANCE MONITORING OF AFRICAN MICRO-GRIDS: GOOD PRACTICES AND OPERATIONAL DATA
}

Xiangkun Li, Samuel Booth, Sean Esterly, and lan Baring-Gould National Renewable Energy Laboratory

Jonathan Clowes and Peter Weston Energy 4 Impact

Parangat Shukla, Jon Thacker, and Arthur Jacquiau-Chamski SparkMeter

January 2020

A product of the USAID-NREL Partnership

Contract No. AID-AFR-T-15-004 


\section{NOTICE}

This work was authored in part by the National Renewable Energy Laboratory, operated by the Alliance for Sustainable Energy, LLC, for the U.S. Department of Energy (DOE) under Contract No. DE-AC3608GO28308. Funding was provided by the United States Agency for International Development (USAID) under Contract No. AID-AFR-T-15-004. The views expressed in the report do not necessarily represent the views of the DOE or the U.S. Government or any agency thereof, including the United States Agency for International Development.

This analysis relies on information provided to NREL by Energy 4 Impact and SparkMeter that has not been independently validated by NREL.

The analysis results are not intended to be the sole basis of investment, policy, or regulatory decisions.

This report is available at no cost from the National Renewable Energy Laboratory (NREL) at www.nrel.gov/publications.

U.S. Department of Energy (DOE) reports produced after 1991 and a growing number of pre-1991 documents are available free via www.OSTI.gov.

Cover photo from SparkMeter.

NREL prints on paper that contains recycled content. 


\section{Acknowledgments}

The National Renewable Energy Laboratory (NREL), Energy 4 Impact (E4I), and SparkMeter would like to thank the Power Africa Beyond the Grid team for its guidance and input throughout this work, especially Katrina Pielli and David Stonehill. We would also like to thank Sam Duby from TFE Energy for sharing his adaptation of the Quality Assurance Framework (QAF) and for his review of this report. Additional thanks go to Eric Lockhart and Tim Reber from NREL for their reviews, as well as to Liz Breazeale, Britton Marchese, and Isabel McCan for editing support. Finally, we would like to thank all the members of the micro-grid development community who offered data, feedback, and time in support of this report. 


\section{List of Acronyms}

AMDA

E4I

NREL

O\&M

QAF
African Mini-grid Developers Association Energy 4 Impact

National Renewable Energy Laboratory operations and maintenance

Quality Assurance Framework 


\section{Executive Summary}

Micro-grids are expected to play a critical role in providing energy access to the roughly 600 million people in sub-Saharan Africa who currently live without electricity. Growth of investments in the sector is necessary but has been slow to materialize. Investment is inhibited by a perception of risk, a lack of proven business models, and a limited understanding of the actual performance of operating systems. Standardized and systematic performance monitoring provides an opportunity to lower risks, validate business models, and demonstrate the technical and financial performance of micro-grids. This report highlights the importance of performance monitoring for micro-grids, focusing on the operations phase of micro-grid projects, as that is when the bulk of the data is generated and most performance monitoring benefits are realized.

Furthermore, this report supports a major need in the micro-grid sector by providing a standardized list of performance monitoring indicators for collection and reporting. These parameters are provided for three key functional areas during micro-grid operation: commercial and financial monitoring; customer/utility accountability; and technical performance. Some examples of these key parameters include: number of customers, system revenues, power costs, energy sales, voltage violations, system downtime, and customer satisfaction. Additionally, this report provides advice on data collection and contains a comprehensive list of metrics from TFE Energy's Quality Assurance Framework (QAF) project with the African Development Bank.

To help demonstrate the potential benefits of performance monitoring, this report also presents the analysis of the performance data of 36 micro-grids (with 4,660 meters) currently operating in Africa, in cooperation with SparkMeter, in one of the largest assessments conducted to date within the sector. Figure ES- 1, Figure ES- 2, and Figure ES- 3 show examples of this analysis, including the types of data that can be collected and the insights that can be developed. Figure ES- 1 shows the percentage of meters across all sites in each QAF service level for energy consumption, power consumption, and power availability (using the proxy of operator defined power limits). Higher QAF service levels indicate higher levels of consumption and availability. The data show that micro-grid operators generally set much higher power limits (largely Level 4) compared to what customers are consuming (largely Levels 1 and 2), in part to incentivize growth. Grid operators can use performance monitoring data to analyze their risk exposure and determine appropriate power limits to ensure systems are not overbuilt or oversubscribed.

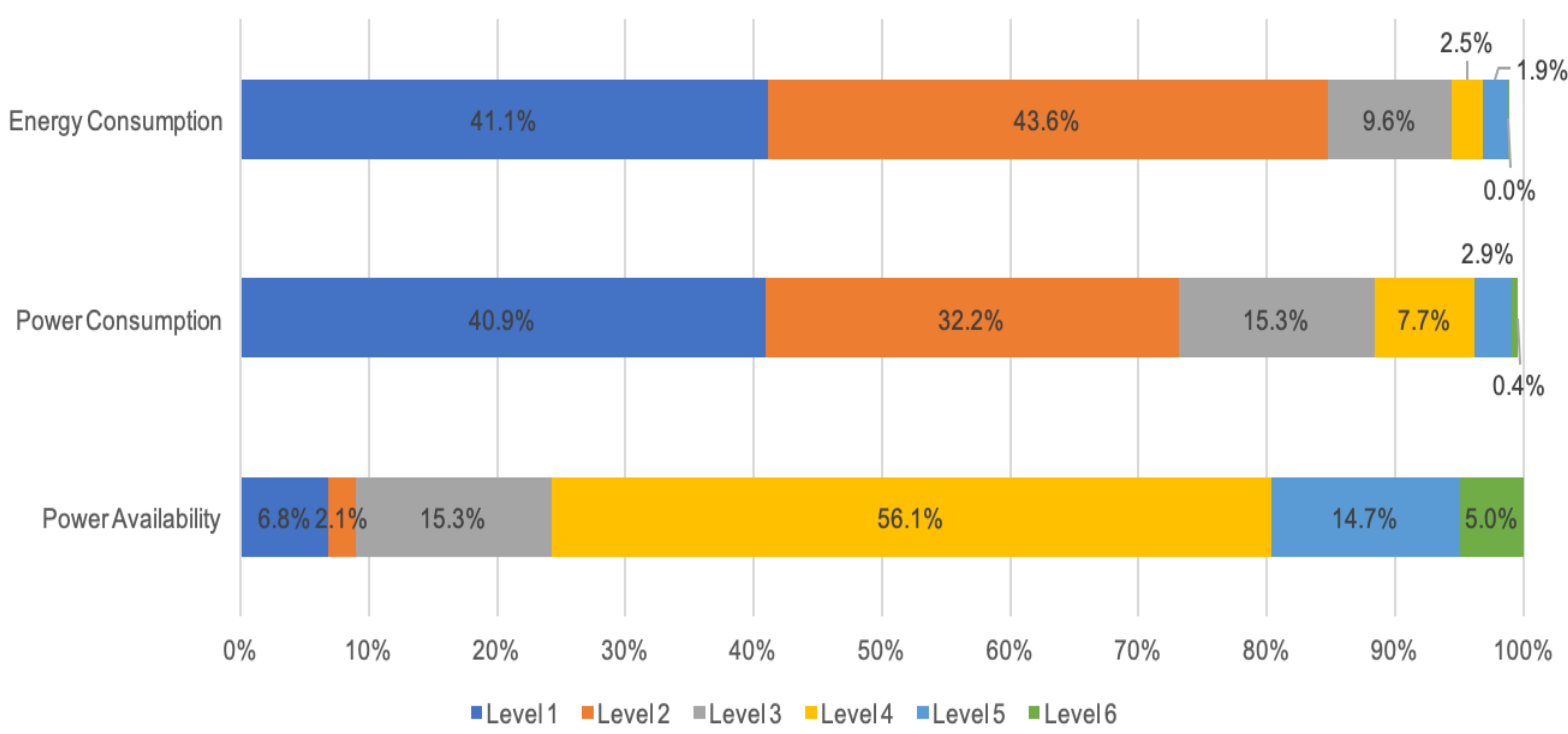

Figure ES- 1. Distribution of meters in QAF service levels for power and energy performance 
Figure ES- 2 shows the distributions of power factor measurements ${ }^{1}$ for all meters at each site. To avoid the disproportionate impact of reactive loads on power factor when active power consumption is very small (e.g., from unused chargers that are plugged into an outlet), the figure only considers power factor measurements when active power draw is greater than $10 \mathrm{~W}$. Power factor values range from a minimum of 0.042 to a maximum of 1 , with median values between 0.6 and 0.7 . Power factors in this range indicate an underestimation of the reactive power demand of the micro-grid system and/or the presence of highly nonlinear loads. This could lead to potential technical issues with supplying reactive power from inverters, and potential revenue issues for developers who only get paid for real power and may want to adjust billing to account for loads that require high levels of reactive power support.

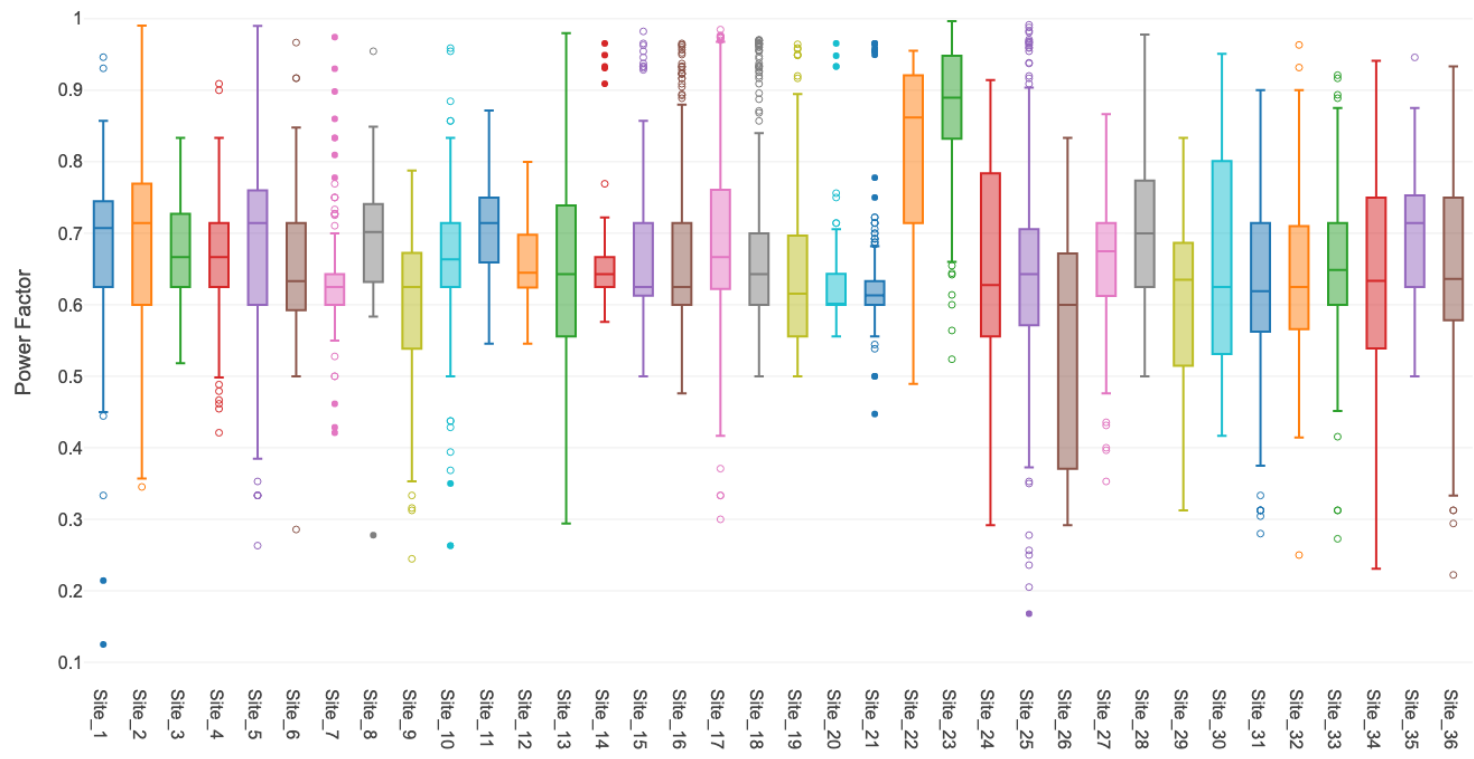

Figure ES- 2. Power factor by site

Figure ES- 3 shows the average frequency profile for a specific site in the SparkMeter data set. The plot on the left shows how frequency varies over a typical 24-hour period with relatively low standard deviation. Frequency appears to follow the trajectory of a typical PV generation profile. We can speculate this is caused by the type of frequency control implemented at the site. Instead of isochronous control to maintain a single frequency setpoint, the site most likely employs droop control, where frequency may take on a range of values in response to changes in load. The site may need to adjust droop control settings to maintain a tighter frequency band. Greater frequency variations across meters are seen on a monthly basis. Because measured frequency should be the same at all meters within a site, these deviations could be caused by differences in the data logged at each meter over a period of a month. For example, data gaps caused by outages or communication systems resetting that only affect a portion of the meters during parts of the day may result in different meters averaging to slightly different monthly frequencies overall. It can also be seen that frequency tends to trend lower in the spring and early summer, particularly in the month of May. This correlates well with the earlier observation that PV generation is typically lower during these months in many African countries due to heavy rains. Reconfiguring inverter settings, introducing anchor loads that primarily consume energy during the day, or adding additional storage to shift PV production to nighttime hours may help to improve the frequency performance of this site. These are just a few examples of the types of analyses that can be done when performance monitoring data is available.

\footnotetext{
${ }^{1}$ Power factor is a measurement of the ratio of real power to apparent power in an electrical system.
} 

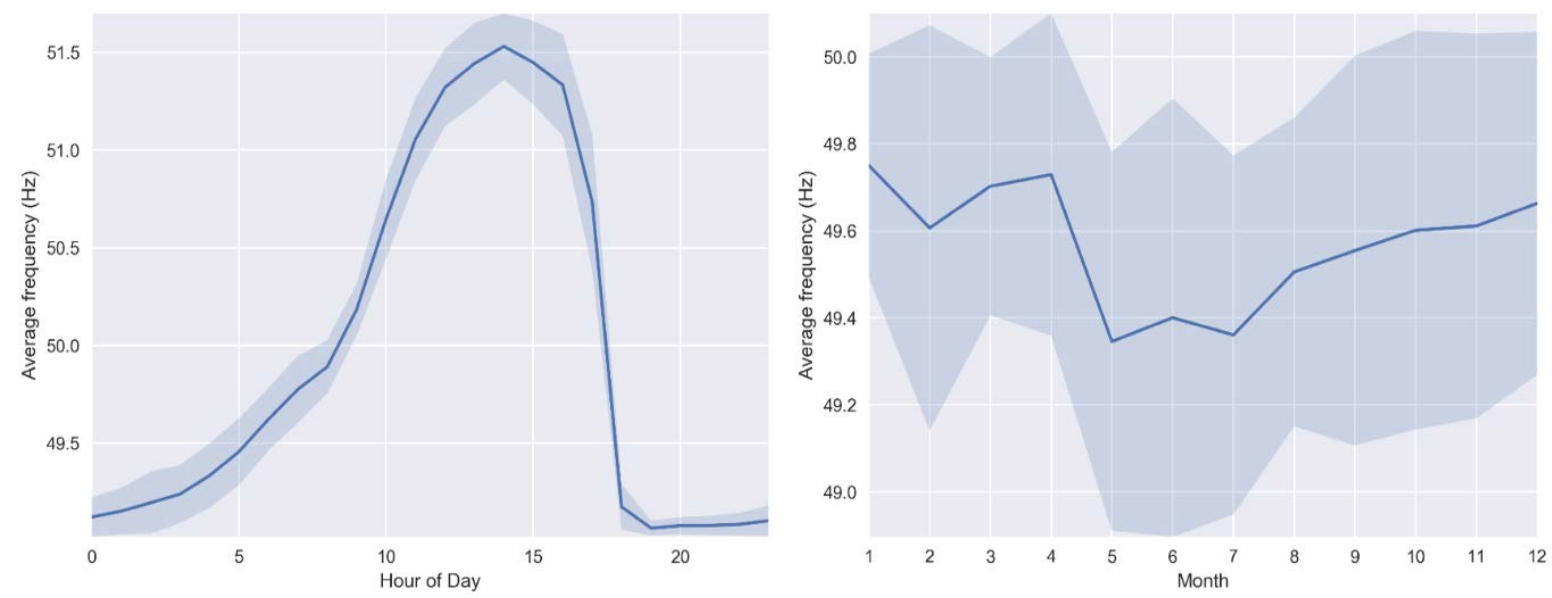

Figure ES- 3. Average frequency profiles at Site 5

This report was developed by the National Renewable Energy Laboratory (NREL) and Energy 4 Impact (E4I) in support of the Power Africa Beyond the Grid Program. It is a companion document to NREL's QAF for Mini-Grids (Baring-Gould et al. 2016).

This report is a resource that developers, donors, investors, and governments can use to understand the benefits of micro-grid performance monitoring. This report presents best practices for conducting performance monitoring along with possible sets of indicators to measure and examples results from performance monitoring activities. To better integrate performance monitoring into the micro-grid sector, this report makes the following recommendations:

- Creation and dissemination of a standardized performance monitoring guide for the micro-grid sector, along with harmonization of the reporting requirements between stakeholders;

- Creation of open source tools to help expedite and streamline analysis and data collection from different devices (e.g., smart meters and inverters from different equipment manufacturers);

- Sharing of performance indicators and data across the industry; and

- Increased training for micro-grid developers and regulators on performance monitoring. 


\section{Table of Contents}

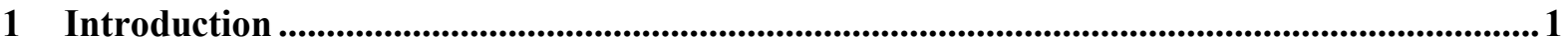

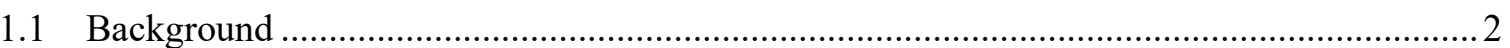

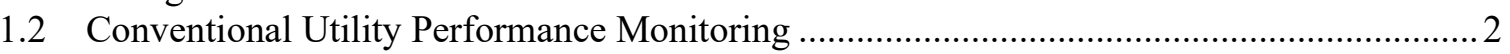

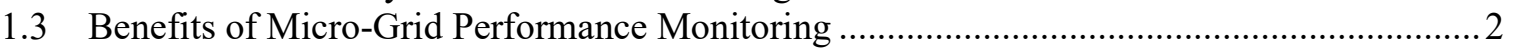

1.4 Desktop Research and Developer/Stakeholder Workshops .................................................. 3

2 The Performance Monitoring Process.................................................................................6

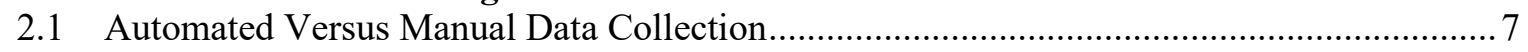

3 Performance Monitoring: Operations and Maintenance ................................................................9

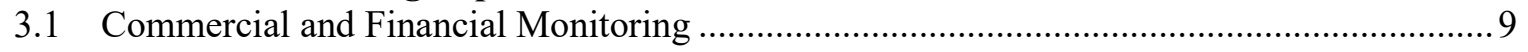

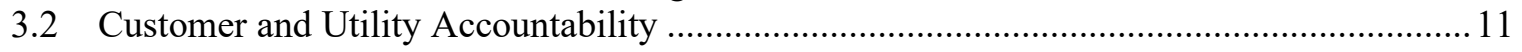

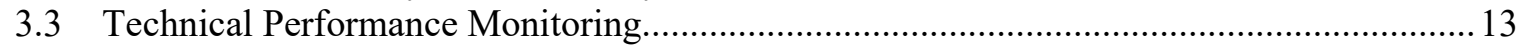

4 Assessing Micro-Grid Technical Performance by Analyzing Meter Data .................................16

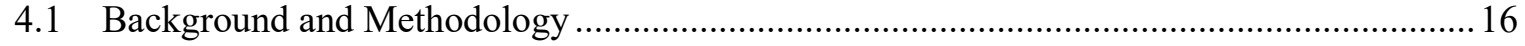

4.2 Observations From Performance Monitoring................................................................... 17

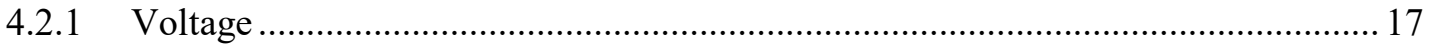

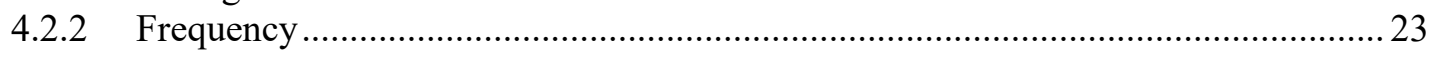

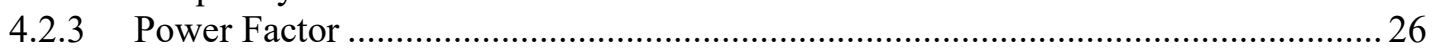

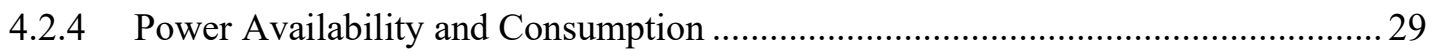

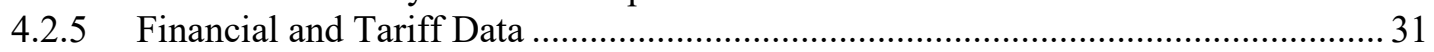

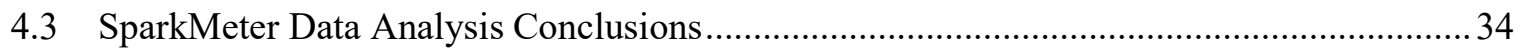

5 Challenges, Lessons, and Recommendations .............................................................................35

5.1 Challenges and Lessons From Collecting and Analyzing Data ............................................. 35

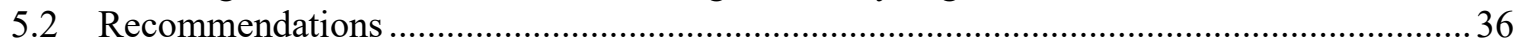

References.....................................................................................................................................................3 37

Appendix A. Data Collection Methodology and Advice ..........................................................................38

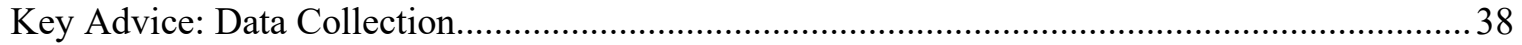

Appendix B. Adapted QAF Metrics for Performance Monitoring in Nigeria ................................40

Appendix C. SparkMeter Data Characteristics .........................................................................................44 


\section{List of Figures}

Figure ES- 1. Distribution of meters in QAF service levels for power and energy performance..........iii

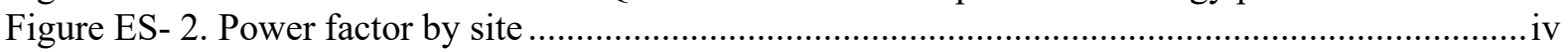

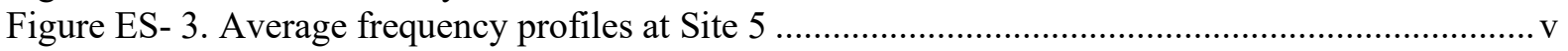

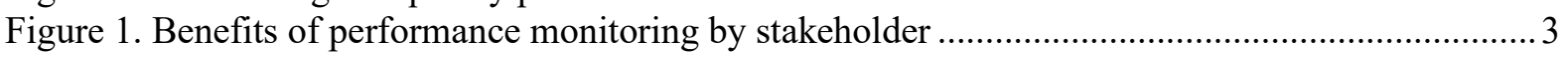

Figure 2. The general performance monitoring process ................................................................. 6

Figure 3. Meters classified into QAF service levels based on maximum and minimum voltages recorded over $100 \mathrm{~ms}$ at the end of each 15 -minute data measurement period .................................. 18 Figure 4. Meters classified into QAF service levels based on 15-minute average voltage

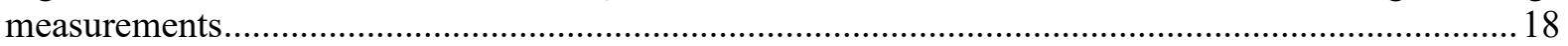

Figure 5. Percentage of meters in each QAF level by site based on maximum and minimum voltages recorded over $100 \mathrm{~ms}$ at the end of each 15-minute data measurement period ................................... 19

Figure 6. Percentage of meters in each QAF level by site based on 15-minute average voltage

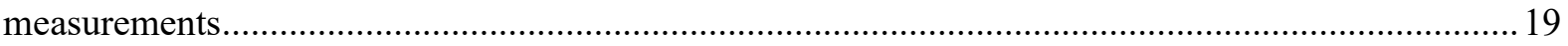

Figure 7. Distribution of all 15-minute average voltage measurements recorded across all meters

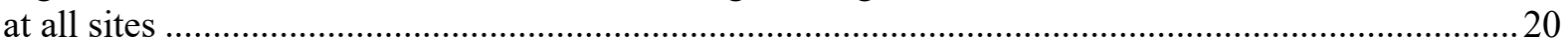

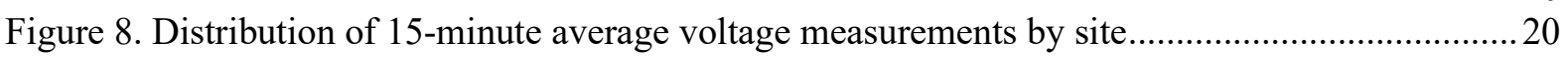

Figure 9. Distribution of voltage performance, taking into account how often violations occur .........21

Figure 10. Voltage performance by month and QAF service level ...................................................22

Figure 11. Average voltage, active power consumption, and frequency profiles at Site $17 \ldots \ldots \ldots \ldots \ldots . .23$

Figure 12. Meters classified into QAF service levels based on frequency performance .......................24

Figure 13. Distribution of all frequency measurements recorded across all meters at all sites ............25

Figure 14. Distribution of frequency performance based on how often deviations occur ....................25

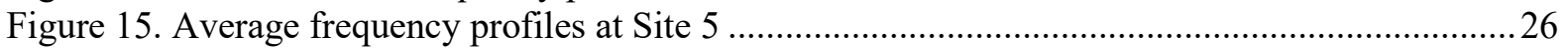

Figure 16. Distribution of power factor values across all the meters at each site ................................2 27

Figure 17. Average consumption and power factor profiles at Site 9 ...............................................28

Figure 18. Distribution of meters in QAF service levels for power and energy performance...............30

Figure 19. Average site load profiles classified into load shape groups ............................................. 31

Figure 20. Changes in electricity cost by average consumption, time of day, and season ....................33

\section{List of Tables}

Table 1. Project Stages and Example of the Importance of Performance Monitoring ........................... 1

Table 2. Comparison of the Pros and Cons of Automated vs. Manual Data Collection.......................... 8

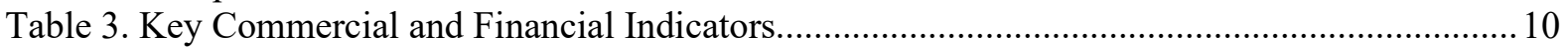

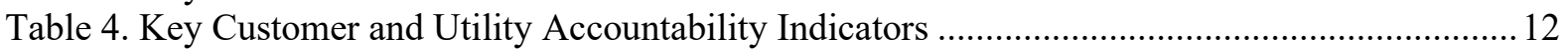

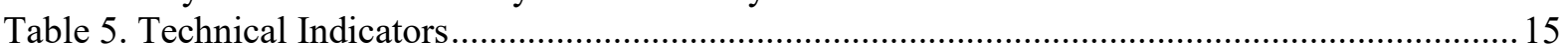

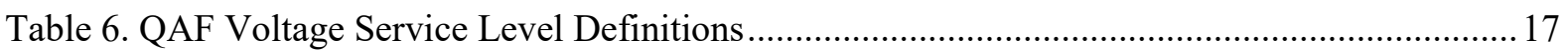

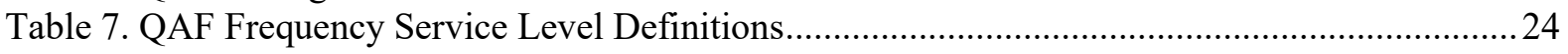

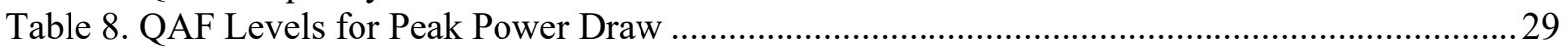

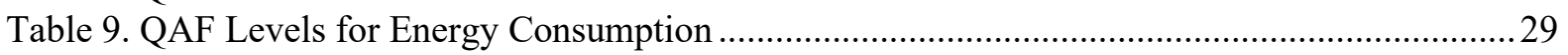

Table A- 1. Example Performance Monitoring Documentation Structure ………............................... 38

Table B- 1. TFE Energy's Adaptation of the QAF into Performance Monitoring Metrics....................40

Table C- 1. Nominal Voltages, Number of Meters per Site, and Period of Data Availability..............44

Table C- 2. Descriptions of the Full Set of Data Parameters Provided by SparkMeter ......................... 45 


\section{Introduction}

An estimated 1.1 billion people - roughly 600 million of whom live in sub-Saharan Africa — still lack access to modern electricity services (IEA 2017). Achieving universal electricity access by 2030 is expected to require an investment of $\$ 52$ billion annually - about half of which is expected to be for micro-grids (IEA 2017). ${ }^{2}$ To successfully mobilize investments, micro-grids must be perceived as having manageable risks and viable business models. Monitoring the performance of systems helps industry stakeholders reduce uncertainty in making decisions related to micro-grid investments, regulations, and policies by providing information on their actual technical and financial performance.

Performance monitoring is the recording, validation, and evaluation of key data to track a developer's or project's performance. It includes the identification of key questions or knowledge gaps and the collection of information. It also includes the identification of issues, actions, and solutions based on the collected information, the implementation of those solutions, and the assessment of their effectiveness. Performance monitoring is important at every stage of a micro-grid project and can generate findings that lead to improvements not only at an individual project level but also at a program or corporate level, where findings from one project are used to enhance multiple other projects. Table 1 provides examples of the importance of performance monitoring at each stage of a micro-grid project.

Table 1. Project Stages and Example of the Importance of Performance Monitoring

\begin{tabular}{ll} 
STAGE & IMPORTANCE \\
\hline Project Design/Development & - Improve demand assessment for systems \\
& - Improve the technical design of systems \\
& - Improve selection of suppliers \\
& - Reduce perceived project risk \\
\hline Project & - Increase chances of smooth project execution by streamlining activities, \\
Implementation/Construction & such as permitting and regulatory compliance \\
& - Increase transparency \\
& - Track budget \\
\hline Operations and Maintenance & - Minimize power system losses, reduce costs, and maximize income \\
(O\&M) & - Understand when system expansion, improvements, or modifications are \\
& - needed to ensure contracted levels of service \\
& - Ensure compliance with regulatory requirements \\
& - Assess socio-economic benefits and areas for improvement \\
& - Build customer trust and satisfaction
\end{tabular}

While performance monitoring is important throughout all stages of a project, it is most crucial and relevant during the O\&M phase, as this is when the bulk of the data is generated, and most monitoring benefits are realized. Therefore, this report focuses on performance monitoring during the O\&M stage of projects. This report is a resource that developers, donors, investors and governments can use to understand the benefits of micro-grid performance monitoring. In the following sections, best practices for conducting performance monitoring are presented, along with possible sets of indicators to measure and example results from performance monitoring activities.

\footnotetext{
${ }^{2}$ For the purposes of this report, a micro-grid is defined as a set of electricity generators that supply a distribution network and provide electricity to a localized group of end customers. The distribution network may or may not be connected to the main electricity grid, but it is able to operate independently of the grid. The terms "mini-grid" and "micro-grid" do not have clear or consistent internationally recognized definitions and are used somewhat interchangeably by many industry stakeholders and practitioners. This report uses the single term "micro-grid" for simplicity but does not attempt to distinguish it from the term "mini-grid," which could also apply in most instances.
} 


\subsection{Background}

This report is one of three publications written by the National Renewable Energy Laboratory (NREL) and Energy 4 Impact (E4I) with support from Power Africa, a U.S. Government initiative coordinated by the U.S. Agency for International Development (USAID). This particular report was also written in collaboration with SparkMeter. NREL and the U.S. Department of Energy have developed a Quality Assurance Framework (QAF) for Mini-Grids. This framework has the dual goals of: (1) defining a range of service levels that ensure safe, quality, and affordable delivery of electricity; and (2) providing an accountability framework that can be used to determine whether an agreed-upon service level has been delivered. This report is a companion document to the QAF and the Quality Assurance Framework Implementation Guide for Isolated Community Power Systems (Baring-Gould et al. 2017).

\subsection{Conventional Utility Performance Monitoring}

Performance monitoring of micro-grids is similar in many ways to performance monitoring of a central grid. Similar technologies are used to measure, collect, and track performance data. However, conventional utility performance monitoring is conducted on a much larger scale, and quality and reliability standards, although they may vary from country to country, are well-established. For example, the North American Electric Reliability Corporation ensures the reliability of the bulk power system in North America and is responsible for both developing and enforcing reliability standards, as well as for monitoring system reliability. The QAF was developed by applying many of the successful principles from the utility sector to the micro-grid sector. There are several qualities of a utility model that if applied to the off-grid market sector in a consistent way for performance monitoring, can help the micro-grid industry. The most important include the standardization of customers, a diversification of risk, and long-term data gathering benefits.

- Standardization of Customers: Since energy use is similar across households and communities, the classification of customer energy needs allows for the aggregation of customers into certain categories based on characteristics such as income or housing type. This aggregation makes it much easier to plan and predict future energy needs and revenues once baseline information has been obtained.

- Diversification of Risk: Utilities are typically well-diversified, with many customers over relatively large areas to limit the impacts of any payment loss or technical issues. While microgrids can be very dependent on local conditions and equipment, a mini-utility or an investor that operates multiple micro-grids with the same development and reporting structures gains diversification that can help reduce risk.

- Long-Term Data Gathering: Successful utilities continuously collect information around energy usage, customer behavior, payments, and reliability. This information not only allows the utility to operate more efficiently but also improves planning and provides a solid financial record, which then greatly reduces the potential risks that concern investors.

\subsection{Benefits of Micro-Grid Performance Monitoring}

Performance monitoring can be used to support developers and other stakeholders in the micro-grid sector. Key potential benefits for different stakeholders are shown in Figure 1. 


\section{Developers:}

- Improve demand forecasting for existing and future micro-grids

-Improve understanding of energy needs and growth opportunities

- Build trust with customers and evaluate customer satisfaction

- Optimize operations by reducing O\&M costs, improving revenue collection, and reducing system losses

-Troubleshoot technical system issues and failures more effectively

\section{Regulators and policy makers:}

-Accurately assess the short and long-term energy needs for a community or region

- Standardize system performance and services across developers

-Document and demonstrate regulatory compliance

\section{Investors and donors:}

- Report and document business models, financial sustainability, and returns

- Measure the socio-economic impacts of micro-grids on the local community

- Improve understanding of risks and risk mitigation opportunities

Figure 1. Benefits of performance monitoring by stakeholder

The case studies in the text box below present two additional examples of the specific benefits of performance monitoring.

\section{Examples of the Benefits of Micro-Grid Performance Monitoring}

\section{O\&M Cost Reduction}

Analysis by AMMP technologies (AMMP 2018) found that remote performance monitoring can reduce O\&M costs by about $15 \%$ for basic monitoring solutions and by about $30 \%$ for advanced monitoring solutions. In these cases, the savings came from reduced component replacements, logistical savings from things like reduced site visits, and reduced labor costs.

Improved Demand Forecasting

Performance data is useful in predicting demand for future micro-grid systems. Many developers currently use surveys for this task. Vulcan Impact Investing examined the results of energy demand surveys and their implications on correct system sizing. Blodgett et al. (2017) compared forecasted demand with actual consumption and found that forecasts were on average more than four times higher. This type of error has led to many oversized micro-grids with reduced financial viability. Many developers have found that predicting demand for future systems with operational performance information from existing systems (e.g., average load per household or typical business loads) is more accurate and less resource-intensive than surveys.

\subsection{Desktop Research and Developer/Stakeholder Workshops}

Background research conducted as part of this report revealed that the information and advice available on performance monitoring for micro-grids is limited. Some information is available, but it is incomplete and there is limited guidance around standard metrics, data collection, and data evaluation. 
To help understand existing performance monitoring practices, meetings were held with developers, and workshops were conducted with micro-grid industry stakeholders. ${ }^{3}$ These meetings sought to gather information by posing three key questions:

1. Why is performance monitoring important?

2. What are the challenges for effective performance monitoring?

3. What are the performance monitoring frameworks currently used? Who enforces these and how effective are they?

A summary of the findings from these meetings and workshops is presented below:

- Internal use of data: Developers agree that the internal use of data is important to improve performance, scale up systems, and grow their customer base. While some developers are collecting data and using it for this purpose, they generally have a limited understanding of what data to collect and how to best use it. Guides, templates, and trainings would be very valuable.

- Standardization: Developers are unaware of standardized data and monitoring requirements across the industry. Data collection requests from stakeholders, including donors, investors, and regulators, are often ad hoc, with developers being asked to report the same data in numerous ways and formats. These requests can be onerous; standardizing data collection requests would reduce the cost of compliance and improve the quality of responses.

- Oversight: There is limited ongoing monitoring from regulators, governments, or donors for many micro-grid projects. It would be beneficial if these stakeholders had standard performance monitoring requirements as a part of a permitting or investment process and if consolidated data was shared across stakeholder groups.

- Data collection: Developers face several challenges in the collection and analysis of data,

○ Technology: There is limited information available to developers on the equipment available to collect data (e.g., how to use smart meters and system inverters to automate data collection). There is a perception that data collection technology is expensive. Training would be helpful in this area.

- Methodology: Developers have received limited guidance on what methodology to use when collecting different types of data. This includes what data should be collected, how it should be collected, the frequency of collection, and so on.

- Resources: Data collection is often a very manual process for many developers, requiring a lot of resources and time to complete.

- Social impact: Measuring the social impact of a project is difficult for developers. Investors and regulators often want this information, and developers generally also want to understand it, but there is no standard framework or indicators for developers to use.

- Analyzing data: Developers struggle to analyze data, as it can cause a strain on resources. Analysis is often done on an ad hoc basis. Developers would appreciate support, training, and tools to create standardized analysis techniques in accordance with reporting requirements.

- Customer feedback: Developers struggle to capture and respond to customer queries, feedback, and complaints. They are aware of the value of this information and would appreciate more guidance on how to collect and use it.

\footnotetext{
${ }^{3}$ E4I and NREL organized performance monitoring workshops for developers and other stakeholders in Dar es Salaam, Tanzania, on December 12, 2017, and in Kampala, Uganda, on January 15, 2018.
} 
- Sector data: Industry-wide benchmarking data is not available. ${ }^{4}$ This creates difficulties for projects during design and implementation, analysis of demand assessment data, and the setting of operational goals and targets.

- Productive use: Developers understand the potential of performance monitoring to help identify the most valuable productive use activities and the most effective ways to encourage them. However, they are unsure how to execute projects or programs based on this data. More information or case studies would be beneficial.

- Assumptions: Developers are currently relying on assumptions when it comes to designing and operating a micro-grid project. They would like to use performance monitoring as a way of validating or improving these assumptions.

${ }^{4}$ Some initiatives, such as Odyssey and Sun-Connect, are starting to tackle this issue. 


\section{The Performance Monitoring Process}

The general performance monitoring process is defined by the seven key steps shown in Figure 2 (although, in some cases, specific steps can be simplified or eliminated if not appropriate).

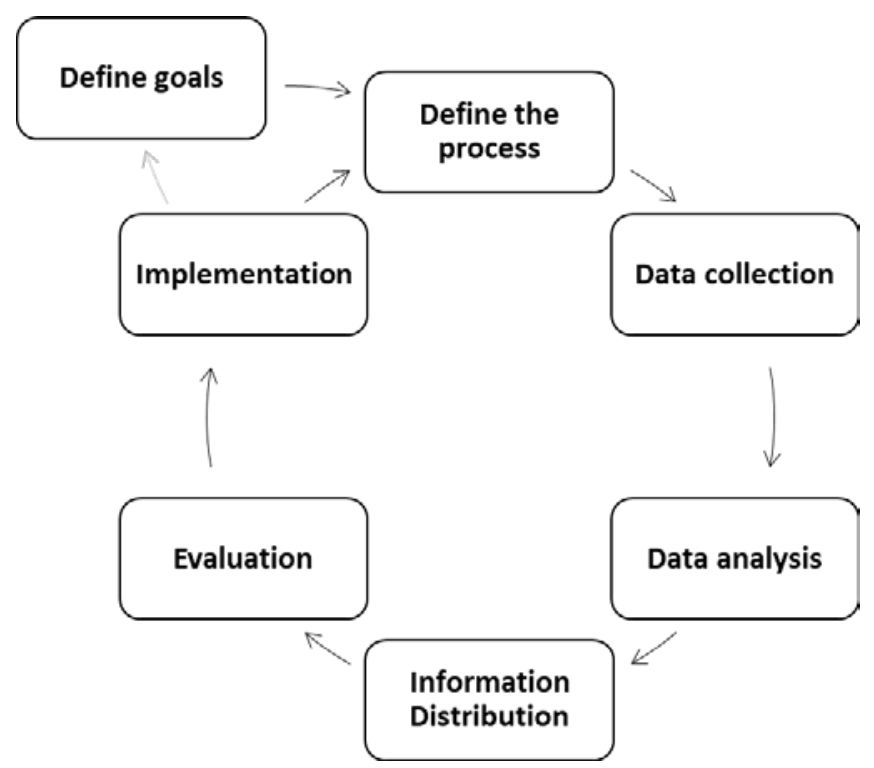

Figure 2. The general performance monitoring process

As seen in Figure 2, the performance monitoring process is cyclical. This shows that performance monitoring is continuous: each time the process is performed, the outcomes can be fed back in to improve the process moving forward. In the development of micro-grid systems, the concept of performance monitoring has typically focused on the collection and reporting of operational performance data for internal and/or regulatory use. It should be noted, however, that in the larger context of project development and implementation, performance monitoring should be employed more holistically. The steps in this process are briefly discussed below:

- Defining Goals: Define the goals the project or program is seeking to achieve.

- Defining the Process: Identify several key indicators against which project or program goals can be measured, along with how the necessary data will be collected. Different goals will require different measurements and/or methodologies, which must be understood and documented. ${ }^{5}$ Furthermore, metrics for evaluating indicators must be defined.

- Data Collection: Collect data using either automated or manual methods (Section 2.1 provides a discussion on automated versus manual data collection). The timely and accurate collection of data is critical to the performance monitoring process, as without good data, meaningful analysis and process improvements are not possible. Section 3 of this report provides examples of the main types of data that should be collected.

- Data Analysis: Verify and analyze the raw data according to predefined analysis techniques. It can be helpful to develop data analysis tools at an early stage of a project to enable efficient and immediate analysis. Data analysis tools should be automated as much as possible and include initial quality control assessments to identify flaws or errors in the data. Data processing tools should also include targets and safety thresholds, alerting analysts if specific parameters deviate outside of defined ranges. Analyses should document both current and long-term performance

\footnotetext{
${ }^{5}$ Data collection and processing can be expensive and resource-intensive. It is important that indicators are only selected if they will be used in the performance monitoring process. The fewer the indicators that need to be collected, the lower the burden of data collection.
} 
trends. Section 4 of this report provides examples of the types of analyses that can be done using performance monitoring data.

- There are currently no standard data analysis tools for the micro-grid industry, but several companies are working on components of this, including SparkMeter, Odyssey Energy, and AMMP, a spin-off from Rafiki Power based on their Asset Management and Monitoring Platform technology.

- Information Distribution and Evaluation: Communicate outputs of the data analysis to appropriate stakeholders according to the predefined plan. Once the information has been communicated, it must be evaluated to identify issues and suggested improvements.

- Implementation: The final step in the cycle is the implementation of recommendations for corrective actions or system improvements. The impact of these changes can then be evaluated through the next round of the performance monitoring process.

- Verification: Any performance monitoring process will need some verification efforts to ensure that the information being collected can be trusted. The use of the data will determine the level of verification required. For example, if the data collection is simply for local use, the developer could conduct an annual sensor calibration. If the data is being collected for regulatory purposes or to validate terms of a financial commitment, additional oversight will likely be necessary. Various methods can be employed to facilitate data validation including, but not limited to, the use of redundant sensors, the implementation of data security protocols, and the use of third-party verification.

\subsection{Automated Versus Manual Data Collection}

The data collection methodology is dependent on the type and frequency of data being collected. A key consideration when collecting technical measurements is whether to install automated data recording instruments or use manual/handheld devices. For example, some data can be collected directly via smart meters or inverters. The decision of which measurement system to use must be made during the development phase of the project so that the appropriate technology can be costed, procured, and installed.

Table 2 provides a comparison between the pros and cons of automated versus manual data collection. 
Table 2. Comparison of the Pros and Cons of Automated vs. Manual Data Collection ${ }^{6}$

- Continuously records a large number of parameters at high frequency

- Automation leads to low resource requirements

- Generally more accurate

- Can collect data at any level depending on the equipment used (e.g., at the customer, feeder, or plant level)

\begin{tabular}{|c|c|}
\hline Cons & Cons \\
\hline $\begin{array}{l}\text { - Upfront cost } \\
\text { - } \quad \text { May require maintenance and planning for end- } \\
\text { of-life reblacements }\end{array}$ & $\begin{array}{l}\text { - Limited in the types of data that can be collected and } \\
\text { the time resolution of the data when compared to an } \\
\text { automated system }\end{array}$ \\
\hline $\begin{array}{l}\text { A mobile network may be required to transmit } \\
\text { the data automatically and frequently along with } \\
\text { associated data transmission costs }\end{array}$ & $\begin{array}{l}\text { - Human resource-intensive; requires proper training of } \\
\text { local staff } \\
\text { - Time consuming and prone to human error in data } \\
\text { collection and entry }\end{array}$ \\
\hline
\end{tabular}

The frequency of data collection will depend on the indicator and type of data collected. In the case of installed data acquisition systems, the frequency of data collection may be defined by the equipment. Due to the automated nature of this set up, the frequency of data collection will have a limited impact on the cost and resource requirements for the project, though it may impact analysis and data storage needs. Additionally, some data may be monitored quite frequently (e.g., at the second resolution) but only stored as longer-term averages with some data statistics (e.g., minimums, maximums, and standard deviations). When collecting manual measurements, the frequency of data collection will need to be defined by the project or informational needs. In the case of manual data collection, the more frequently the data is collected, the higher the cost and resource requirements for the project.

In addition to quantitative data, it is important to collect qualitative information regarding system operation. For example, this data can be collected through a simple template that plant staff fill in at the end of a shift, detailing any irregularities that would not be captured by the quantitative data. Qualitative data can provide context for quantitative data, for example, by providing the reason for a disruption or the rationale for shutting down a feeder, helping to identify the root cause of an issue. See Appendix A for additional details and best practices on data collection methodologies.

\footnotetext{
${ }^{6}$ Manual data recording in this context refers to sending trained local/on-site personnel to manually record measurements (e.g., power quality or consumption data) directly from system equipment (e.g., inverters, customer meters) or at end-use premises using handheld devices.
} 


\section{Performance Monitoring: Operations and Maintenance}

The O\&M phase of a project is when the bulk of performance monitoring activities take place. Specific activities will vary depending on the goals of a particular project, but common parameters can be identified. When considering the operations of a commissioned micro-grid, performance monitoring can be broadly split into three major functional areas:

- Commercial and financial monitoring

- Customer and utility accountability and demand monitoring

- Power quality, reliability, and availability monitoring.

A single performance monitoring process is likely to fall across functional areas, requiring inputs from each during its design and implementation. Each of these functions are presented below with suggested indicators, descriptions of how performance monitoring can be used to improve the activities of each function in a micro-grid project, and case studies. Much of this information is derived from the QAF.

In a related effort, TFE Energy is working with the African Development Bank to adapt the QAF to provide performance monitoring and reporting parameters for projects in Nigeria. Details of the parameters and other key information, such as data sources and suggested collection frequency, can be found in Appendix B. This is a detailed resource that could be especially valuable to developers or regulators looking to implement a performance monitoring program.

\subsection{Commercial and Financial Monitoring}

The commercial and financial functions of an operating micro-grid vary depending on the business model of the project, but main activities are similar. The first critical function is accounting for and tracking costs and revenues, the bulk of which for a micro-grid is payments from customers for connections and power. The main goal of this task is to ensure customer payments are received, and all costs are documented (typically for company accountability and tariff justification). Another key goal is to help identify areas of potential cost savings and income maximization. Examples of key commercial and financial indicators for performance monitoring are shown in Table 3. 
Table 3. Key Commercial and Financial Indicators

\begin{tabular}{ll} 
INDICATOR & UNITS \\
\hline Number of customers & $\#$ \\
\hline New connections & $\# /$ month \\
\hline Potential unconnected customers & $\#$ \\
\hline $\begin{array}{l}\text { Monthly payment collection rates (number of payments/number of } \\
\text { customers) or customers behind on payments }\end{array}$ & $\%$ \\
\hline Total energy sales revenue & USD $/$ month \\
\hline $\begin{array}{l}\text { Other revenues (e.g., from other services offered, monthly service } \\
\text { charges, or connection fees) }\end{array}$ & USD/month \\
\hline Average monthly revenue per user & USD/month \\
\hline Cost per connection & USD/connection \\
\hline Total cost of power & USD/kWh \\
\hline Total losses (kWh generated/kWh sold) & $\%$ \\
\hline
\end{tabular}

These data can be used to prepare financial reports and for budgeting, forecasting, or other decisionmaking processes. Additionally, this information is needed for communication to investors and other stakeholders on the project. The amount of time spent on reporting is also an important metric for assessing the performance of commercial and financial functions over time.

\footnotetext{
${ }^{7}$ Although USD is used in this example, other currency values could of course also be used. It may be helpful to track these values independently in the local currency or the currency through which the project is financed. To the extent possible, a very stable currency unit should be used, as currencies that fluctuate will make it harder to see trends related to the cost of energy services for specific projects or programs.

${ }^{8}$ Revenue data should be disaggregated by service level and sector.
} 


\section{Commercial Performance Monitoring Case Study}

E4I provided technical assistance to a micro-grid developer operating a solar-diesel hybrid plant. As part of the work with the developer, E4I analyzed the performance of their commercial and financial processes to identify areas for improvement. The E4I team found that the developer was collecting a comprehensive list of commercial and financial indicators, but the commercial department had no time or capacity to fully utilize this data. E4I worked with the developer to understand how they could implement a reactive performance monitoring process to free up resources within the department.

The major goal identified by the commercial team was reducing the amount of time spent on reporting each month. This would give the commercial team time to identify activities that could increase plant profitability rather than just focusing on business as usual activities. The key indicator that the developer missed was the amount of time spent compiling and analyzing the data for each part of the report. Data for this indicator was collected retroactively by analyzing previous reporting cycles. Once the data was collected and evaluated, it became clear that there were two major data sources that accounted for roughly $40 \%$ of the time spent on reporting. The first was income data from the local bank where customers make payments and the second was income from mobile money payments. Initiatives were developed to reduce the time spent compiling and analyzing these data sets, including training the department generating the data to provide the data in the correct format, improving data analysis tools, and standardizing reporting templates. By implementing these changes to the reporting process, the commercial team was able to save five days of staff time each month. The team is now working on fully utilizing the existing data to identify project improvement opportunities.

\subsection{Customer and Utility Accountability}

Micro-grid projects have numerous stakeholders. Performance monitoring is vital to ensure the project maintains strong relationships with all stakeholders and that the flow of information between stakeholders is robust and consistent. Stakeholder engagement can be broadly categorized as customer and utility accountability. These concepts are explained in detail in the QAF and summarized below.

Customer accountability involves the enforcement of the agreement between the customer and the provider of energy services. Customer accountability performance monitoring helps to ensure that the expected service is provided, strengthening consumer confidence. This in turn increases a customer's willingness to pay for service and hence the overall sustainability of a project. Additionally, performance monitoring can be used to analyze the impact of productive use strategies by monitoring the power consumption of different customers, businesses, and appliances over time. It is then possible to identify the most appropriate trainings, businesses, and appliances a project should focus on to generate the highest revenue.

Utility accountability refers to the agreement between the provider of energy services and the government, regulator, or funders. Utility accountability performance monitoring impacts the collection and dispersal of information about the system. It can help ensure set procedures are in place to guarantee the safety of staff and customers. It is crucial that a project monitors the effectiveness of these activities over time to ensure they remain up-to-date and relevant. Utility accountability information can be used by the service provider to improve operational management and facilitate long-term energy planning.

Performance monitoring can also be used to evaluate the impact of marketing and sales activities by tracking changes in the number of connections. Additionally, effectively monitoring complaints and queries received can shed light on a project's performance and produce recommendations for improvements that reach far beyond a specific customer. Example key indicators, outside of those already provided in the last section, that can play a specific role in understanding customer and utility accountability, are shown in Table 4. 
Table 4. Key Customer and Utility Accountability Indicators

\begin{tabular}{ll} 
INDICATOR & UNITS \\
\hline Performance of the project against the service level agreement with customers & description \\
\hline Annual electricity production & $\mathrm{kWh}$ \\
\hline Renewable energy penetration (renewable kWh/total kWh) & $\%$ \\
\hline Duration of daily service & hours/day \\
\hline Number of complaints & $\#$ \\
\hline Number of safety incidents & $\# /$ month \\
\hline Power consumption (disaggregated by customer, service level, and type) & $\mathrm{kWh} / \mathrm{month}$ \\
\hline Number of new connections per month & $\# /$ month \\
\hline Number of disconnections per month & $\# /$ month \\
\hline Percentage of the community connected & $\%$ \\
\hline Increases in the number of products and services available in the local community & $\#$, description \\
\hline Sample appliance ownership by customer & appliance type \\
\hline Customer satisfaction & $\begin{array}{l}\text { Ranking (e.g., } \\
1-5) \text { from } \\
\text { surveys }\end{array}$ \\
\hline Customer trainings on energy usage & $\#$ \\
\hline
\end{tabular}


- Power plant performance monitoring measures the performance of specific systems or components within the power plant of a micro-grid, such as bus voltages and the performance of batteries, PV systems, and/or other generators. This level of monitoring can be used to assess component performance, calculate metrics such as renewable energy penetration levels, and assist in the troubleshooting of technical problems. This type of information is most commonly gathered from the system inverter.

Key indicators, outside of those already provided in the last two sections, that can play a specific role in understanding power system and power plant performance are shown in Table 5. This list is generally broken down into metrics that track electrical and power system issues and other information needed to understand and mitigate these potential electrical problems. Many of these parameters are defined over specific time thresholds, which are dependent on local business or operational requirements and are therefore not explicitly defined here. Additional details on technical performance monitoring can be found in the QAF. 
Table 5. Technical Indicators

\begin{tabular}{ll} 
INDICATOR & UNITS \\
\hline Number of planned power outages & $\#$ \\
\hline Number of unplanned power outages & $\mathrm{hh}: \mathrm{mm}$ \\
\hline Length of power outage & liters \\
\hline Amount of fuel used & $\mathrm{kWh}$ \\
\hline Power generated &
\end{tabular}

Battery performance (with various indicators, depending on focus):

- Battery voltage-for state-of-charge and safety information VDC

- Current in and out-for system performance information A

- Battery efficiency_for system efficiency information \%

- Battery temperature-to monitor battery health $\quad{ }^{\circ} \mathrm{C}$

\begin{tabular}{|c|c|}
\hline Average power factor & $\mathrm{kW} / \mathrm{kVA}$ \\
\hline Voltage imbalance & $\%$ \\
\hline Transients & \# \\
\hline Voltage variations & \#/day \\
\hline Frequency variations & avg deviation in $\mathrm{Hz} /$ time \\
\hline DC ripple & $\%$ \\
\hline Average power & $\mathrm{kW}$ \\
\hline Maximum power & $\mathrm{kW}$ \\
\hline Average number of hours in a day that power is available & hours/day \\
\hline Time of power availability & time \\
\hline $\begin{array}{l}\text { System Average Interruption Frequency Index } \\
\text { (planned and unplanned) }\end{array}$ & $\begin{array}{l}\text { Total number of customer } \\
\text { interruptions/total number } \\
\text { of customers }\end{array}$ \\
\hline $\begin{array}{l}\text { System Average Interruption Duration Index } \\
\text { (planned and unplanned) }\end{array}$ & $\begin{array}{l}\text { Total minutes of customer } \\
\text { interruptions/total number } \\
\text { of customers }\end{array}$ \\
\hline Type of event & Predefined category \\
\hline Cause of event & Predefined category \\
\hline Outcome of event & Predefined category \\
\hline Date and time of event & Date, hh:mm \\
\hline
\end{tabular}

Section 4 presents a case study of technical data collection and analysis. 


\section{Assessing Micro-Grid Technical Performance by Analyzing Meter Data}

The objective of this case study, completed in partnership with SparkMeter, is to help illustrate the type of information that can be gathered from a robust performance monitoring assessment and analyze the performance of existing micro-grid systems across sub-Saharan Africa using QAF metrics as indicators.

\subsection{Background and Methodology}

This analysis was conducted using SparkMeter data from 36 sites across three sub-Saharan Africa countries: Kenya, Nigeria, and Tanzania. Sites were selected to ensure diversity in consumption patterns, average loads, and number of connections. Data from 4,660 smart meters covering 6-12+ months of data were considered. ${ }^{9}$ A few key features of the data set are listed below:

- All readings analyzed were recorded after May 2016 from unique customer meters.

- Data was recorded at 15-minute intervals, measuring parameters such as voltage, frequency, power factor, active power consumption, user power limits, and electricity cost. Some data points were average measurements over each 15-minute period, while other parameters were instantaneous values recorded over $100 \mathrm{~ms}$ at the end of each 15-minute period. See Appendix C for a full list of data parameters and detailed descriptions on how they are sampled.

- Of the 36 sites, 19 sites covered a data measurement period of over 12 months, and 17 sites covered a period of 6-9 months. Although not all meters reported data for the full measurement period, a large amount of data was still available for analysis, far more than has ever been used in previous studies to understand the actual performance of operating micro-grids in Africa.

- Of the 36 sites, 26 have a nominal voltage of $230 \mathrm{~V}$, and 10 have a nominal voltage of $240 \mathrm{~V}$. All sites operate at a frequency of $50 \mathrm{~Hz}$.

- All readings were from single-phase AC connections.

- Source of electricity generation, power system topology, and customer type (e.g., residential, commercial, or industrial) were unknown as SparkMeter does not record such information.

An analysis of the performance of these SparkMeter systems using the QAF framework is provided in the sections below. The QAF was developed to evaluate multiple parameters and categorize microgrid performance into different service levels depending on the quality of service. The QAF has components addressing power quality, power availability, and power reliability. When considering electrical power quality, the QAF based its defined levels of service on international standards and the typical power requirements of different electrical devices. The defined levels provide a range from high, ostensibly at grid parity (considering a well-resourced and well-maintained national grid), to basic, which represents a safety-based minimum. Power availability refers to the amount of energy service provided to the customer. Here QAF service level classifications align with the multi-tier framework for measuring energy access as defined by the World Bank. Power reliability represents how consistently the power system provides power, and measures quality of service based on the frequency and duration of planned and unplanned outages. Because metering data by itself does not contain information on whether outages were planned or unplanned, and the available dataset did not assign specific causes to periods of missing data, reliability was not the focus of this analysis. Other data parameters of interest, including power factor and electricity rates, without explicit service level classifications in the QAF, were also analyzed.

\footnotetext{
${ }^{9}$ See Appendix C for a breakdown of the number of meters and the nominal voltage at each site and the specific periods over which data is available.
} 
To help illustrate the types of analyses that are possible when performance monitoring data are available, the level of service for a range of data parameters for each of the 4,660 meters was examined using QAF parameters. Acknowledging that the QAF is not the only way to analyze and track performance data, the following sections also present a few other ways to review smart meter data. These are intended to be illustrative examples and do not represent a comprehensive list of analysis methods as the needs for each project, location, and regulatory environment may vary.

\subsection{Observations From Performance Monitoring}

The following sections discuss key observations and interesting results from the analysis of the SparkMeter data set. Classifications of meters under the QAF definitions are first presented followed by other ways of visualizing and interpreting the data. The analysis presented here indicates that the levels of service identified by the QAF are reasonable, though there are systems that do not meet even the basic power quality provisions identified. It should be noted that the results in some cases are not necessarily statistically significant due to the small number of sites, the varied ages of the readings, and the possible differences in operating practices followed by different developers.

\subsubsection{Voltage}

The QAF defines long duration voltage disturbances as deviations greater than $10 \%$ from the nominal system voltage that last longer than one minute. Repeated over- and under-voltage events can cause overheating, damage to consumer equipment, and customer dissatisfaction. Table 6 specifies the number of long-duration disturbances allowed per time period under each defined level of service within the QAF. An additional level, Level 4, was added to capture systems that fell outside the range of the Base level of service. This metric is based on the "worst day of the period": if a meter measures over 10 voltage disturbances during any day over the period, it is categorized as service level 4 overall. The specific time period over which voltage service levels are evaluated is not explicitly defined in the QAF as relevant durations may vary depending on site conditions and monitoring goals.

Table 6. QAF Voltage Service Level Definitions

\begin{tabular}{ccc} 
LEVEL OF SERVICE & QAF LABEL & DEFINITION \\
\hline 1 & High & $<1$ voltage disturbance/day \\
\hline 2 & Standard & $<5$ voltage disturbances/day \\
\hline 3 & Base & $<10$ voltage disturbances/day \\
\hline 4 & - & $\geq 10$ voltage disturbances/day \\
\hline
\end{tabular}

The performance of each connection monitored by a meter in the SparkMeter data set was categorized into one QAF service level based on the maximum number of voltage disturbances in a single day over the provided data set (covering 6 months to over one year of data). Figure 3 and Figure 4 show the percentage of meters at each service level, aggregating all 36 sites. Because SparkMeter data sampling frequencies do not correspond exactly to the 1-minute timescale of the QAF definition, two sets of results are presented. Figure 3 counts voltages disturbances per day based on the maximum and minimum voltage recorded over a $100 \mathrm{~ms}$ period at the end of each 15-minute data measurement period. Figure 4 considers deviations based on the average voltage measured over each 15 -minute period. 


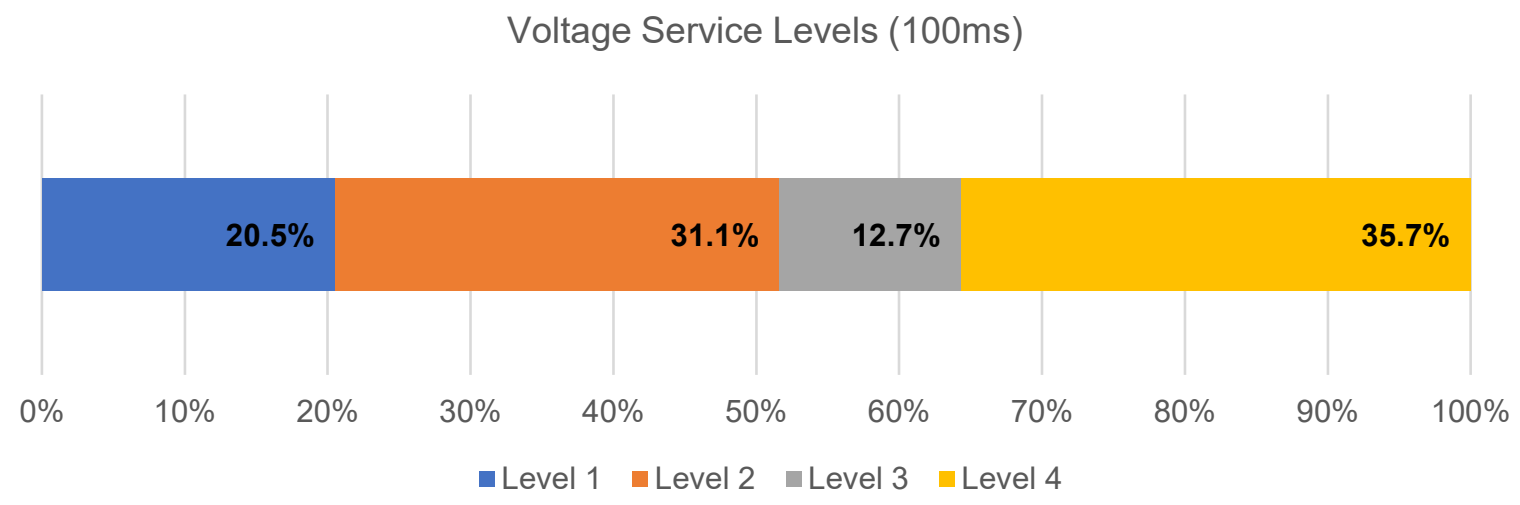

Figure 3. Meters classified into QAF service levels based on maximum and minimum voltages recorded over $100 \mathrm{~ms}$ at the end of each 15-minute data measurement period

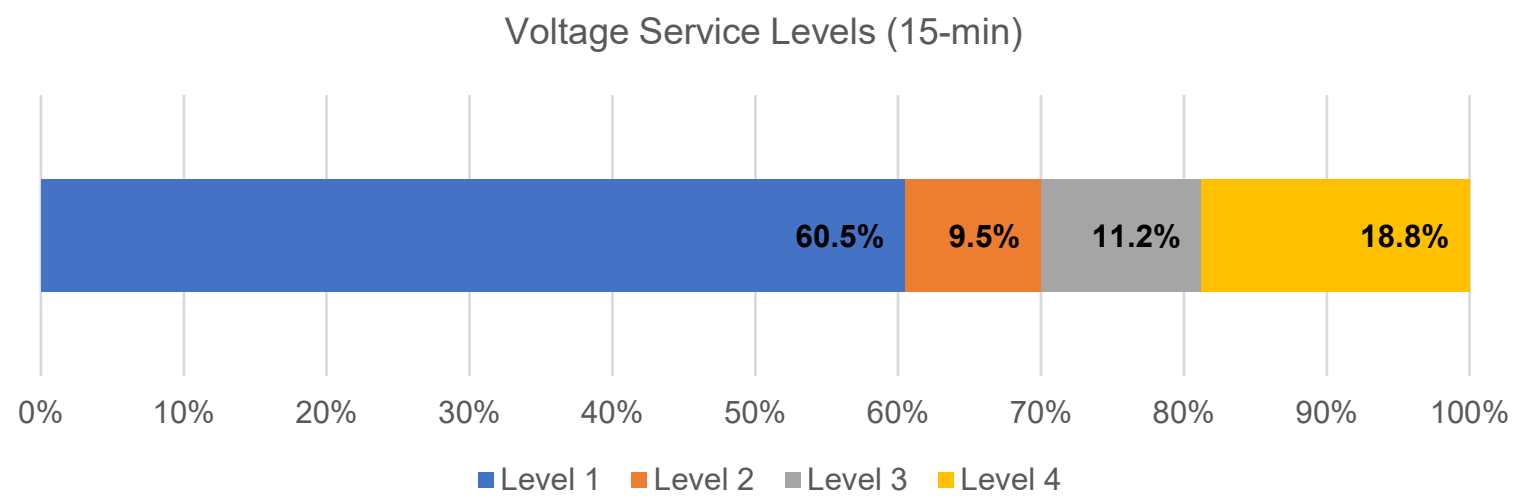

Figure 4. Meters classified into QAF service levels based on 15-minute average voltage measurements

Using voltage data from the $100 \mathrm{~ms}$ measurements, a fifth of the meters were classified as providing Level 1 service, with no voltage violations within the measured data period, while more than a third of the meters were classified as Level 4, outside of the range of the QAF Base service level. Because voltage fluctuations on the timescale of milliseconds might not always signal broader systemic power quality issues, deviations were also analyzed considering 15-minute average voltage measurements. At the 15-minute timescale, the number of meters providing Level 1 service increases significantly to over $60 \%$. However, nearly $20 \%$ of meters are still classified as Level 4 , which means they fell below the safety-based minimum specified in the QAF for at least one day during the period of analysis. The causes of the voltage excursions at these meters should be identified to ensure safe system operation as frequent voltage swings greater than $10 \%$ from nominal at the 15 -minute timescale could signal or lead to serious power quality and safety concerns.

Figure 5 and Figure 6 further break down meter service level classification by site. Figure 5 is based on the maximum and minimum voltages recorded over $100 \mathrm{~ms}$ at the end of each 15 -minute data measurement period, and Figure 6 is based on 15-minute average voltage measurements. In analyzing the data, it was found that small sites with less than 100 meters exhibited fewer deviations in their voltage readings. One potential cause for this could be related to decreased distances between the power plant and customer meters, resulting in a reduced voltage drop measured at the customer meters leading to better overall performance. No definite patterns could be observed for sites with more than 100 meters.

System developers could take similar information and investigate why almost all meters at certain sites within a portfolio (e.g., Sites 11, 19, and 23) exhibit such poor voltage performance, even at the 
15-minute timescale. Potential causes, such as a generation mix with high levels of variable sources, poor distribution system design, and errors in demand predictions, may be common across multiple sites, so solutions only need to be identified once and systematically applied to improve the performance of multiple projects. Developers can also focus on mitigating problems at specific meters within a site that are performing much worse than average (e.g., Site 4). For example, meters at the end of long distribution lines experience a greater voltage drop, resulting in poorer voltage profiles.

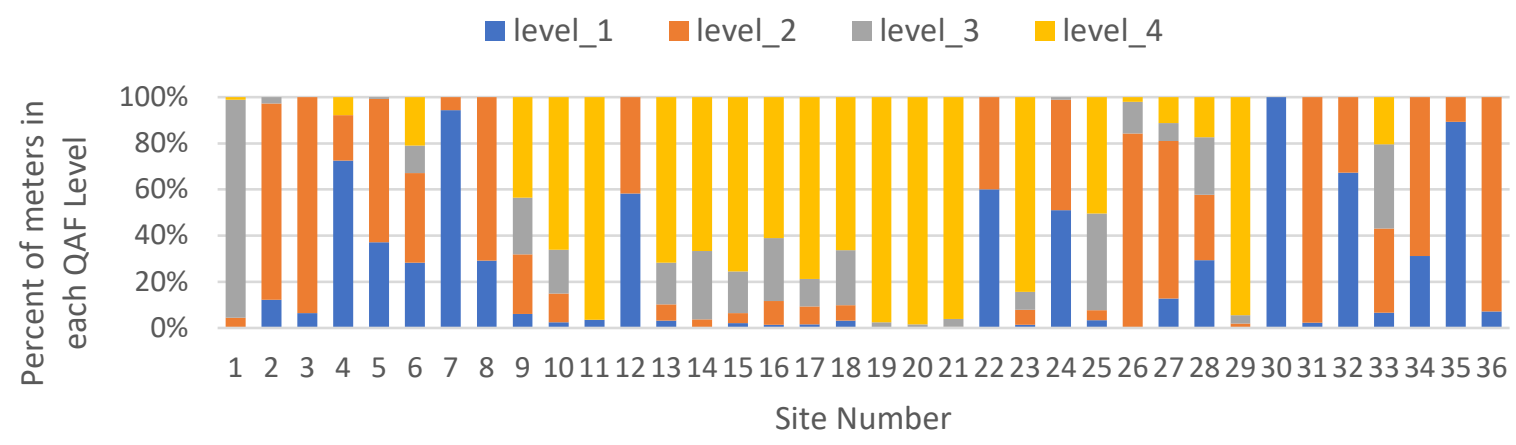

Figure 5. Percentage of meters in each QAF level by site based on maximum and minimum voltages recorded over $100 \mathrm{~ms}$ at the end of each 15-minute data measurement period

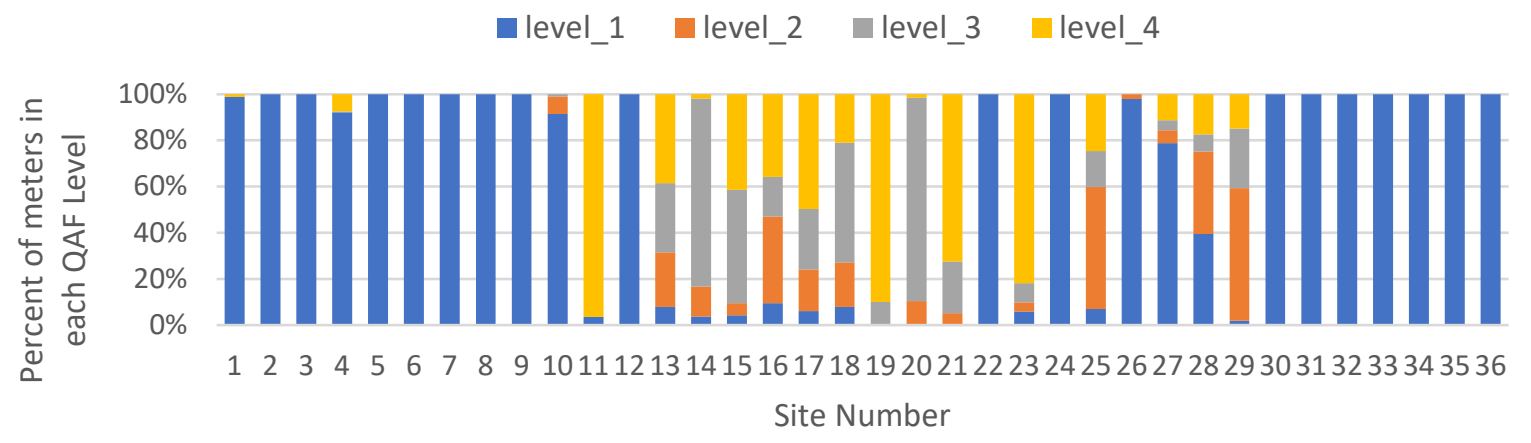

Figure 6. Percentage of meters in each QAF level by site based on 15-minute average voltage measurements

Because the QAF does not explicitly define time frames for occurrence, service levels were assigned on the basis of the worst performing day in the data set. Therefore, a single day with an abnormal number of deviations over a long period of high voltage quality can significantly lower a meter's service level classification. Additional ways to visualize voltage performance, taking into account how often violations occur, are shown in Figure 7, Figure 8, and Figure 9.

Figure 7 shows the distribution of 15 -minute average voltage measurements recorded at all meters across all sites. It shows that voltage excursions above or below $10 \%$ of nominal are relatively rare, meaning days with a large number of voltage deviations are infrequent. Furthermore, the data shows that most voltage violations are voltage sags, dropping down to a minimum of 0.8 p.u., while overvoltage events rarely exceed 1.05 p.u.

Figure 8 shows the distribution of 15 -minute average voltage measurements by site. In the box plot, the central rectangle shows the range of the middle $50 \%$ of voltage measurements at each site, with the median represented by a line that divides the box into two sections. The upper and lower whiskers mark the expected minimum and maximum data points, and outliers are shown as dots. Sites with the greatest variance in voltage measurements or median values furthest from nominal (e.g., Sites 13, 16, 17,18 , and 25) can be singled out for more detailed analyses. This representation also allows 
developers to pinpoint sites that may have tight voltage control but set a system voltage different from the expected nominal voltage of the region (e.g., Sites 19, 20, and 21).

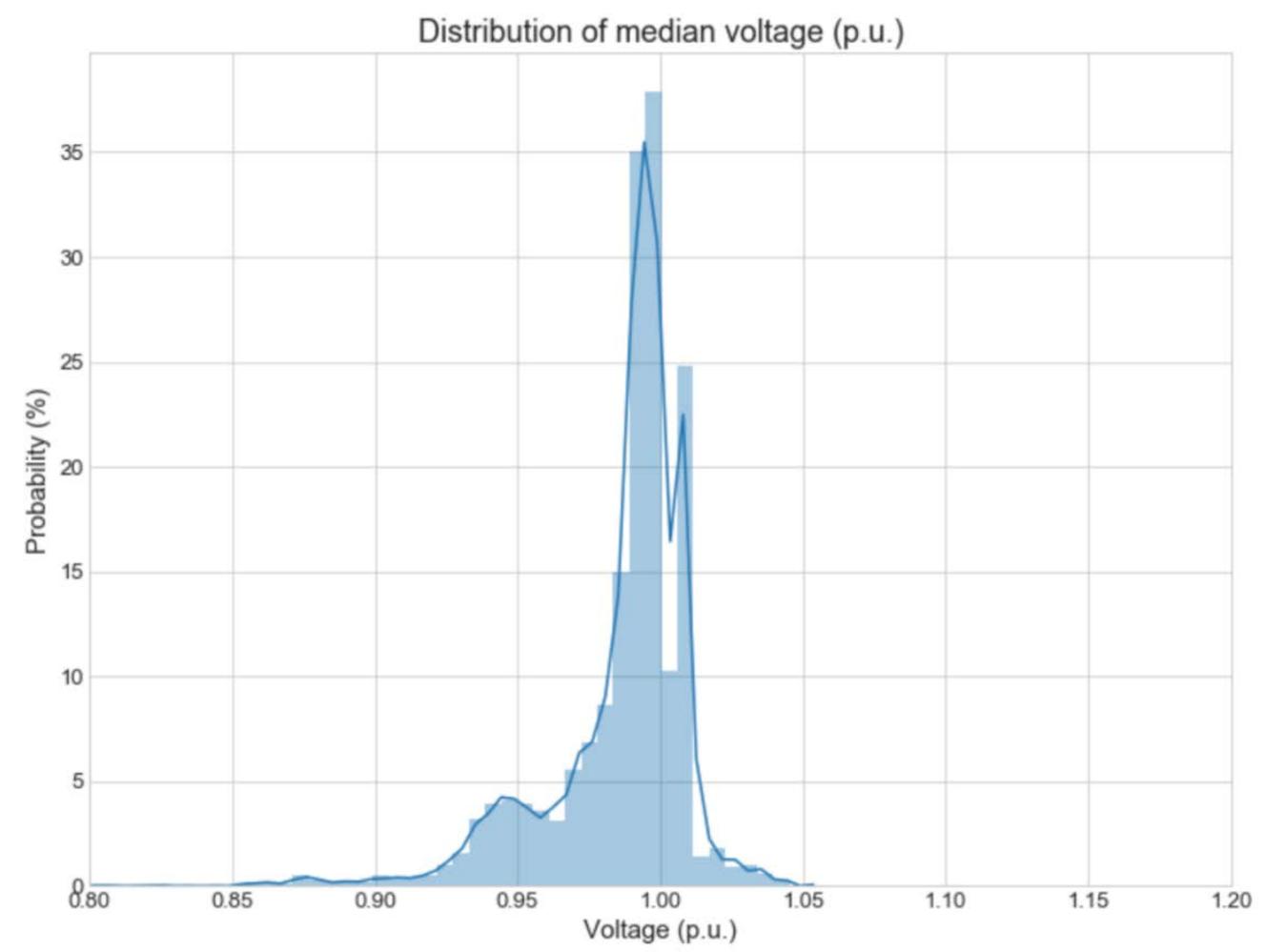

Figure 7. Distribution of all 15-minute average voltage measurements recorded across all meters at all sites

Distribution of median voltage (p.u.)
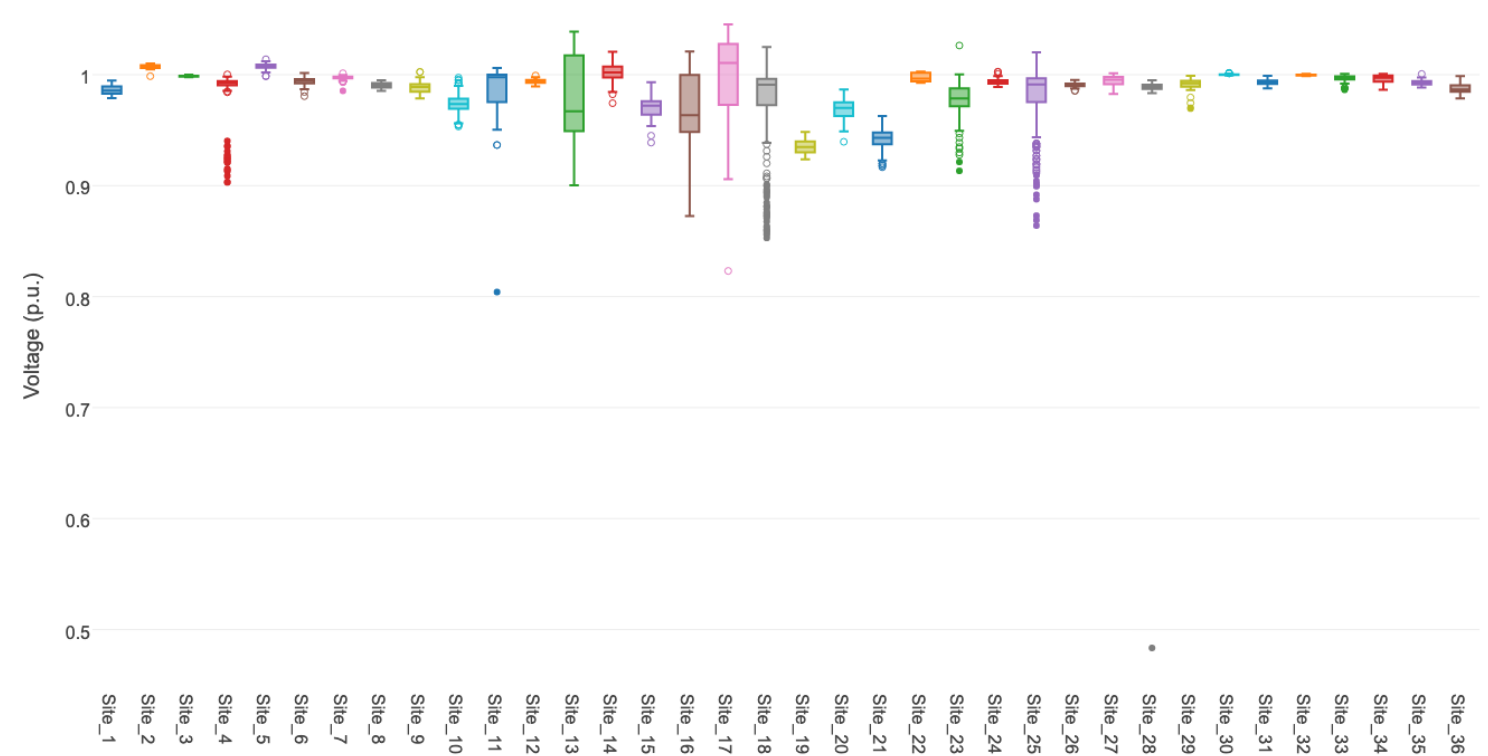

Figure 8. Distribution of 15-minute average voltage measurements by site

Figure 9 further breaks down voltage violations by capturing the QAF voltage service level each meter falls under for each day in the dataset. Instead of assigning a single service level to each meter 
for the entire data period, a service level was assigned to each meter for each day based on the QAF voltage service level definitions in Table 6 .

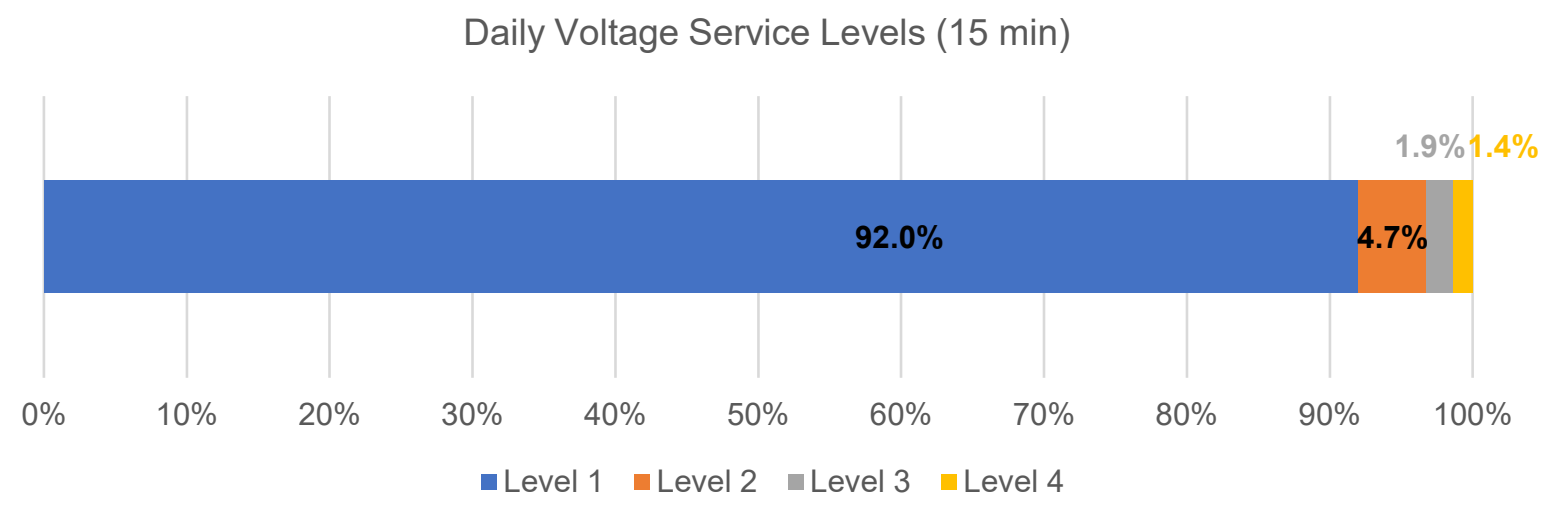

Figure 9. Distribution of voltage performance, taking into account how often violations occur

This additional analysis shows the quality of voltage service is typically high, with measurements falling into Service Level $192 \%$ of the time. While $18.8 \%$ of meters were classified as having Level 4 voltage service when considering the entire data period (Figure 4), this represents only $1.4 \%$ of the days in the dataset (Figure 9). Although these days with over 10 voltage violations at the 15 -minute timescale do not happen extremely often, they fall outside of the Base level of service and may cause safety risks and damage to equipment. This shows that most isolated systems can operate with very little voltage variations, but in systems with significant issues, steps should be taken to improve power quality to avoid damage to consumer and power system equipment and other risks.

To obtain further insights into the voltage performance across the 36 sites, the distribution of voltage measurements was also plotted by month and QAF service level (Figure 10). Systems seem to perform worse in the spring, particularly the month of May. The cause of this is unknown but does seem to correlate with the rainy season in many African countries. For example, April and May are the two rainiest months in Kenya (World Bank Group 2019). Additionally, these months often have the lowest overall solar resource, limiting power generation potential. It is possible that the lower production of solar energy coupled with more hours spent indoors by micro-grid customers during the rainy season resulted in increased energy use that strained micro-grid system performance; however, the most extreme outliers in May at Service Level 4 are the result of a few connections with poor performance at a single site and the specific trend does not generalize across all sites. 

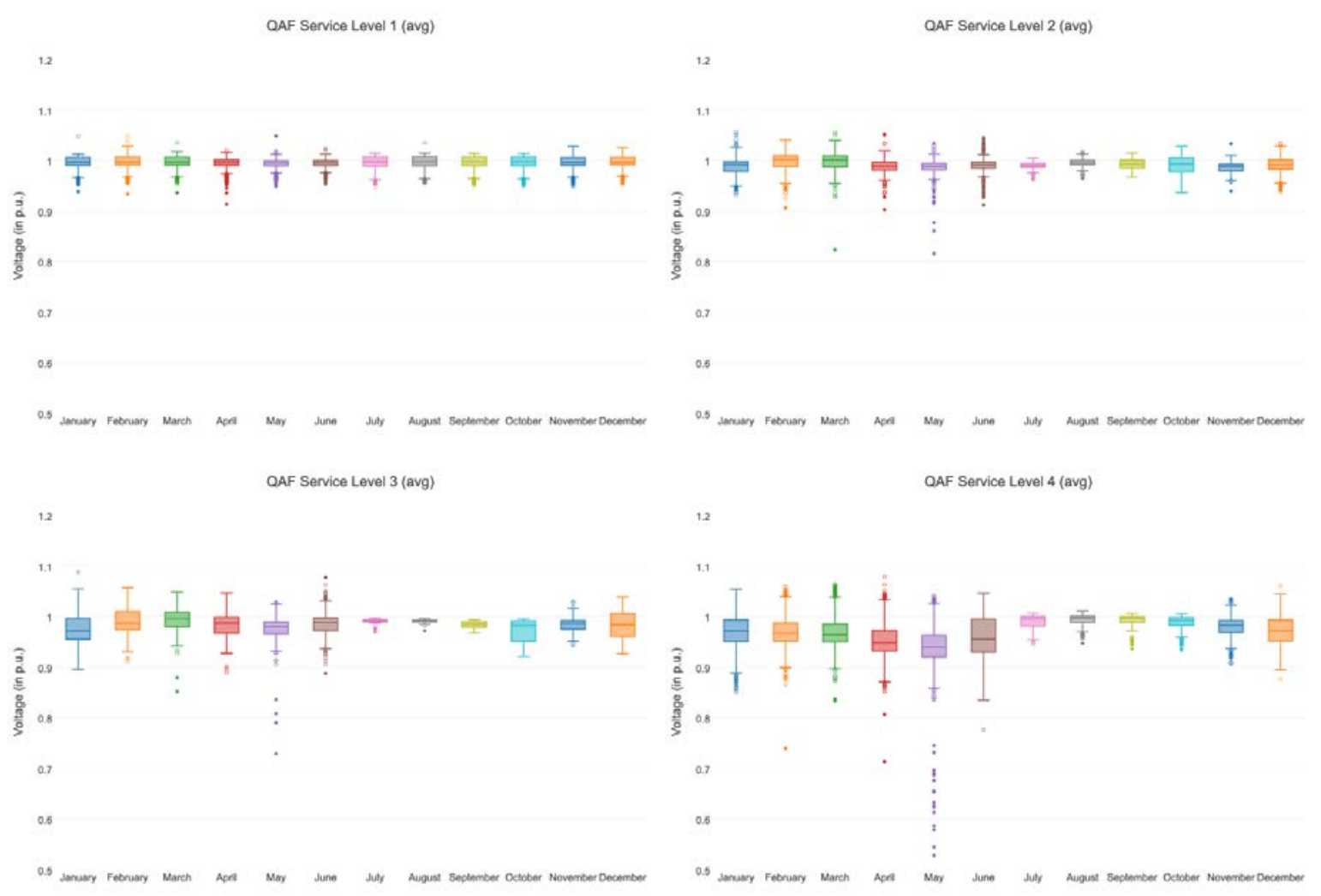

Figure 10. Voltage performance by month and QAF service level

Besides portfolio-level analyses, looking at performance across all sites, we can focus on a single site to analyze the specific causes of its voltage concerns. Taking a more detailed look at Site 17 in Figure 11 , we can see that voltages are typically high throughout the night, rising on average to nearly 1.04 $\mathrm{pu}$ (Figure 11-top, the shaded region represents the standard deviation of voltage measurements across all of the meters at the site). Because the nominal voltage at this site is $240 \mathrm{~V}$, the voltage supply at many meters may exceed $250 \mathrm{~V}$. Although these deviations do not fall within the QAF definition of a long duration voltage disturbance, $250 \mathrm{~V}$ is often used as the upper operating limit for many appliances. Grid operators should monitor these types of voltage deviations to ensure customer safety and safe device operation. Without additional information on generation sources and system configuration, it is difficult to speculate on potential causes, but we can observe correlations to other power system variables to gain insight. System voltages track closely with power consumption, dipping whenever consumption peaks (Figure 11-middle). Frequency is relatively stable at $50 \mathrm{~Hz}$ despite consistently high nighttime voltages (Figure 11-bottom). The two frequency spikes seem to correspond to voltage dips, possibly due to a generator with high sensitivity to voltage drops responding to feedback by quickly spinning up. Because there are no obvious excursions with other system variables, we can speculate that one reason for the high nighttime voltages may be due to setting a constant nominal voltage at the point of generation that is too high for nighttime consumption levels. It is possible the system was expected to have higher nighttime loads with larger voltage drops over the lines, but nighttime demand was lower than expected, causing overall system voltages to rise. These are the types of questions that system operators and developers can analyze using performance monitoring data. 

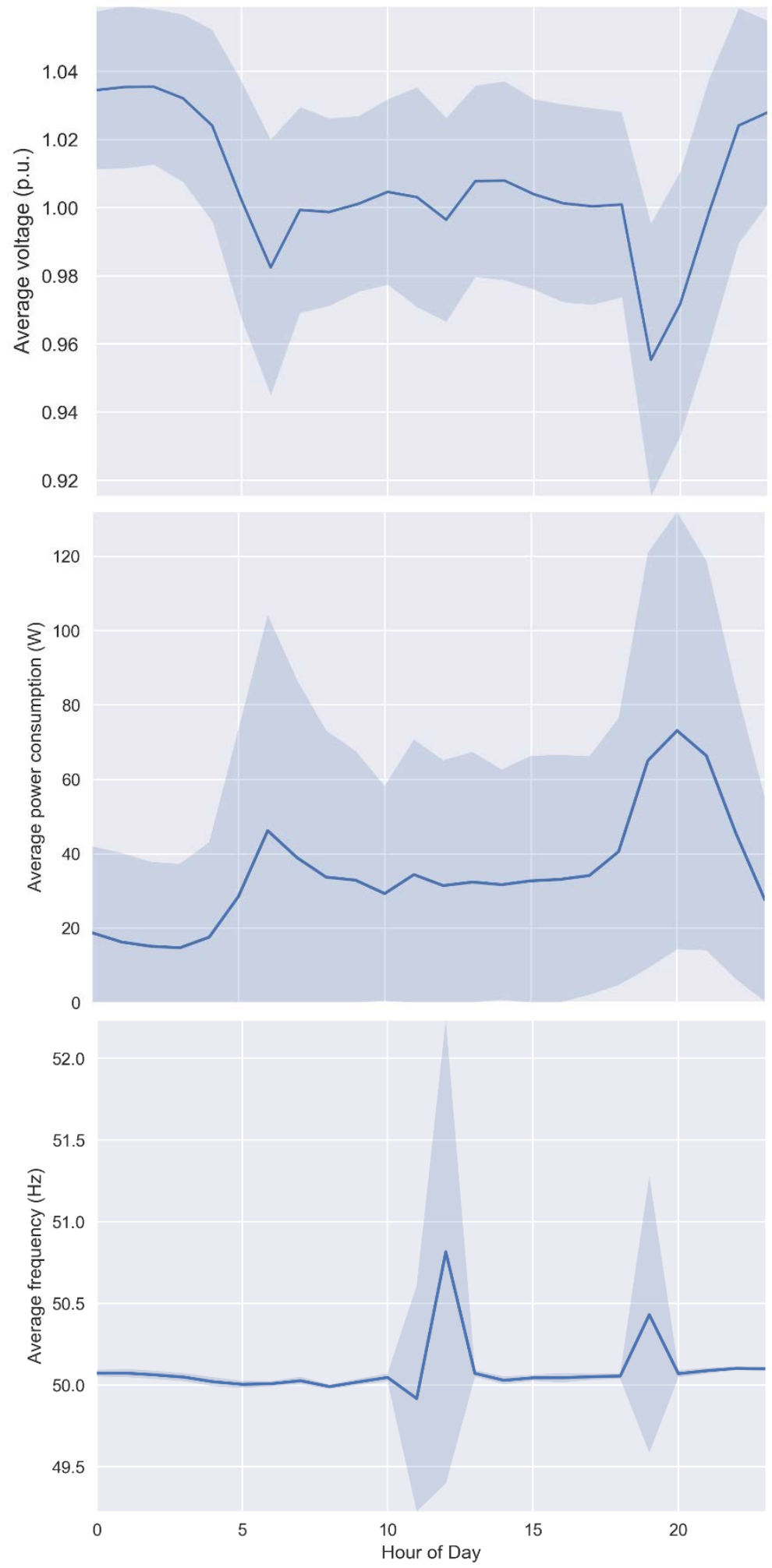

Figure 11. Average voltage, active power consumption, and frequency profiles at Site 17

\subsubsection{Frequency}

Frequency variations are caused by large unexpected changes in load or generation and are typically more prevalent in high variable generation systems or isolated networks. These variations can slow down or speed up motor loads, leading to equipment damage if large excursions are maintained for extended periods of time. The QAF segments frequency measurements into ranges centered around 50 $\mathrm{Hz}$ (Table 7). Quality of service is determined by how tightly system frequency can be kept around 
the nominal value. Similar to voltage service level definitions, an additional level, Level 4, was added in this analysis to categorize systems that perform worse than the defined Base level of service.

Table 7. QAF Frequency Service Level Definitions

\section{LEVEL OF SERVICE QAF LABEL DEFINITION}

\begin{tabular}{ccc}
1 & High & $49.5 \mathrm{~Hz}<\mathrm{f}<50.5 \mathrm{~Hz}$ \\
\hline 2 & Standard & $49 \mathrm{~Hz}<\mathrm{f}<51 \mathrm{~Hz}$ \\
\hline 3 & Base & $48 \mathrm{~Hz}<\mathrm{f}<52 \mathrm{~Hz}$ \\
\hline 4 & - & $\mathrm{f} \leq 48 \mathrm{~Hz}$ or $\mathrm{f} \geq 52 \mathrm{~Hz}$
\end{tabular}

A service level was assigned to each meter based on the single lowest or highest frequency measurement over the provided data period. Figure 12 shows the distribution of meters by QAF frequency service level. Almost a quarter of the total meters are categorized as below the Base level of service, which means they recorded a frequency below $48 \mathrm{~Hz}$ or above $52 \mathrm{~Hz}$ at least once during the period considered in the study.

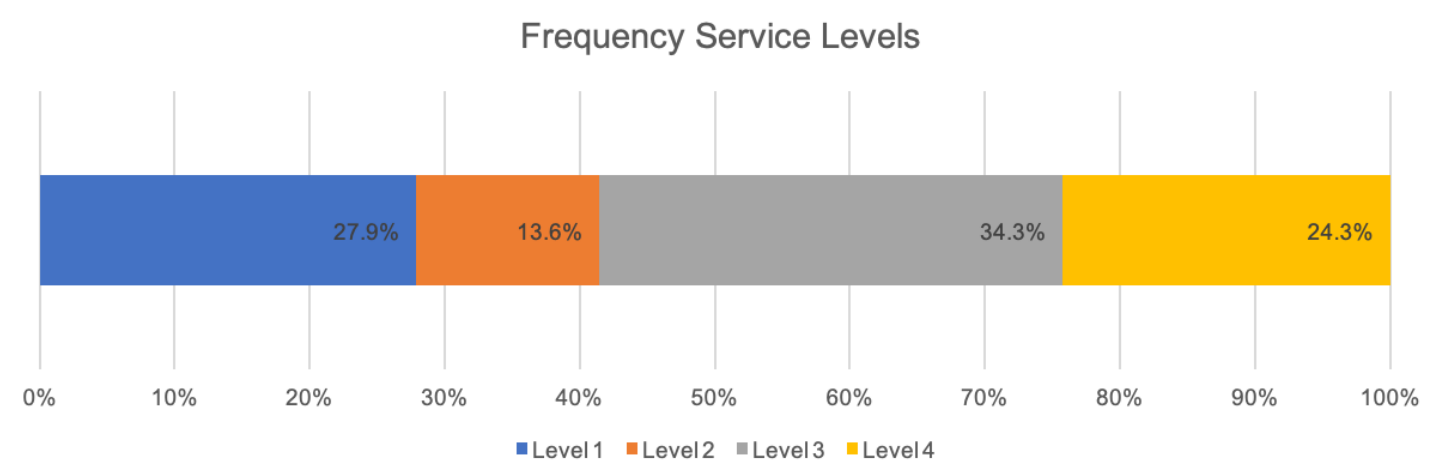

Figure 12. Meters classified into QAF service levels based on frequency performance

Because service-level definitions do not depend on how often excursions outside of the defined bounds occur, a single major event over an extended measurement period can dramatically lower the overall service level of a meter. Additional ways to visualize frequency performance across the microgrid sites based on how often deviations of different magnitudes occur are shown in Figure 13 and Figure 14. Figure 13 shows the distribution of frequency measurements recorded at all meters across all sites. Figure 14 breaks down how often measurements are expected to be within different frequency ranges on average across all sites; instead of assigning a single service level to each meter for the entire data period, a service level was assigned to each frequency measurement data point based on the QAF frequency service level definitions in Table 7. 


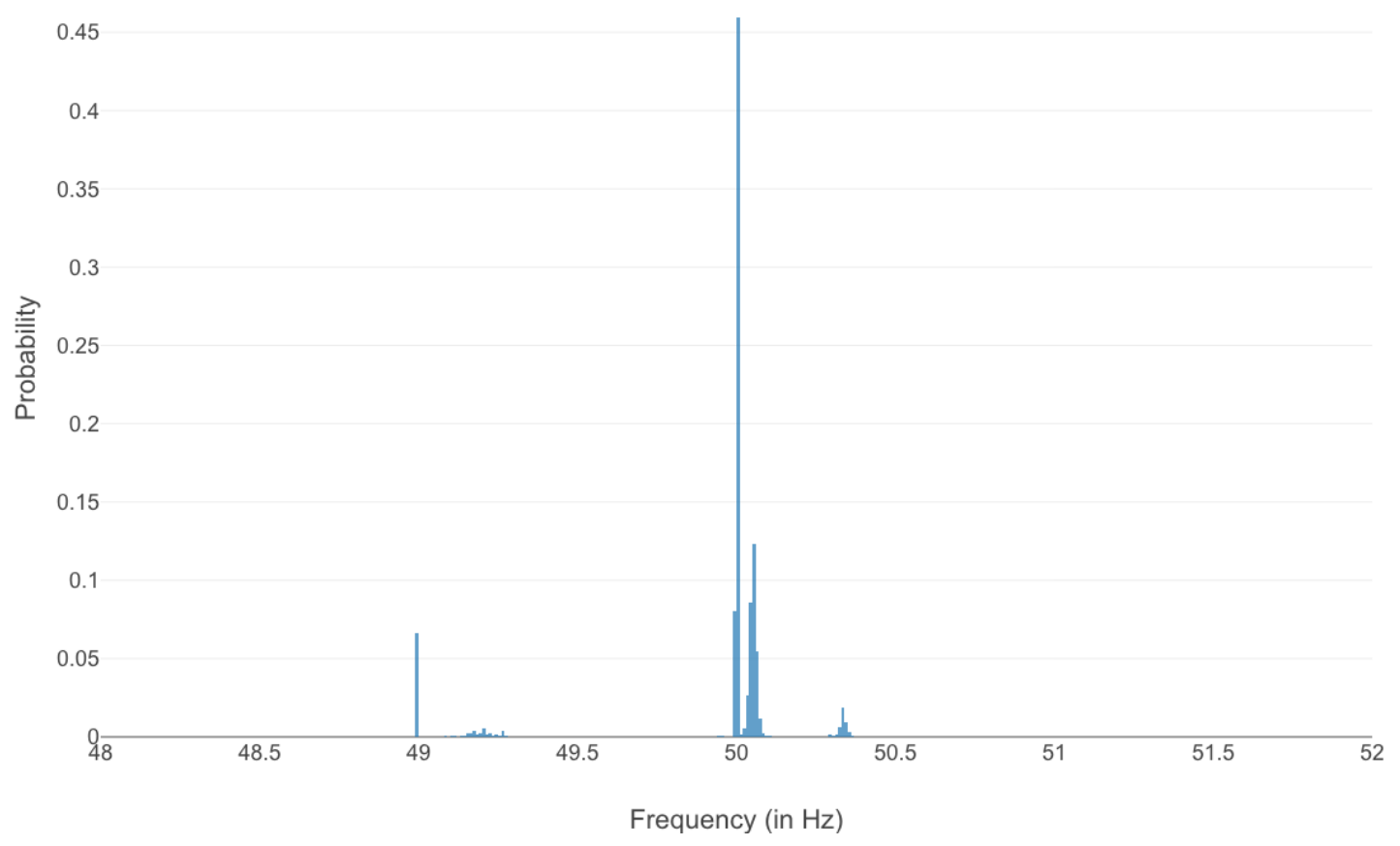

Figure 13. Distribution of all frequency measurements recorded across all meters at all sites

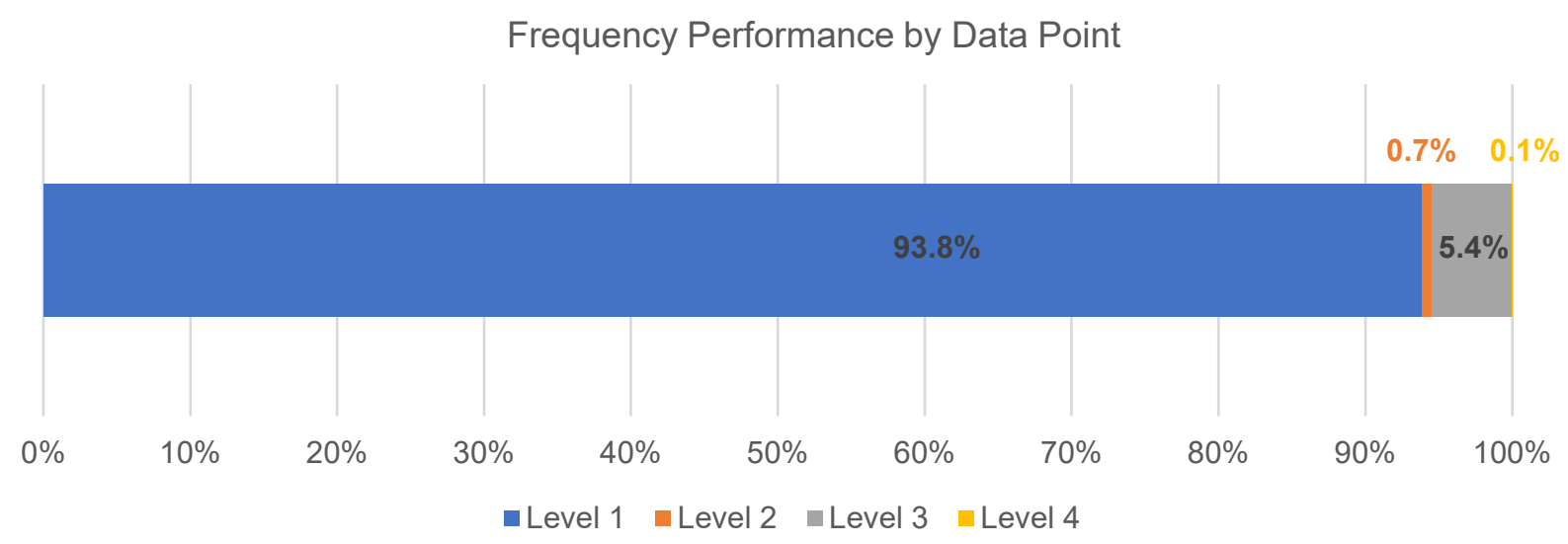

Figure 14. Distribution of frequency performance based on how often deviations occur

Results show that the quality of frequency service is typically high, with measurements falling into Service Level $193.8 \%$ of the time. Approximately $58 \%$ of frequency deviations from nominal are under frequency measurements below $50 \mathrm{~Hz}$. While extreme frequency excursions beyond predefined safety limits are small, occurring in $0.1 \%$ of data measurements, these have the highest potential to cause operational challenges and grid disturbances. Without knowing additional details of the power systems showing poor performance, it is difficult to draw conclusions as to why satisfactory frequency regulation could not be maintained sometimes. These sites may have low quality or older generator technology, or the frequency setpoint in these systems may not have been appropriately set or allowed to drift during early system operation. Site-specific reasons for why large deviations are occurring should be identified so mitigation methods can be implemented to improve overall system performance.

Taking a more detailed look at site-level operation, Site 5 was found to have the system with the highest percentage of frequency measurements that deviate from nominal. Figure 15 shows the average daily and average monthly frequency profile of the system taking into account a year of data. The shaded area represents the standard deviation of frequency measurements across all of the meters at the site. 
A clear pattern emerges of how frequency varies over a typical 24-hour period with relatively low standard deviation across the 367 meters in the system. Frequency starts to rise in the morning and continues climbing before peaking in the early afternoon; this is followed by a steep decline in the evening around 5 p.m. While it is difficult to ascertain the exact causes of this behavior without additional information, it appears that frequency follows the trajectory of a typical PV generation profile. We can speculate this is caused by the type of frequency control implemented at the site. Instead of isochronous control to maintain a single frequency setpoint, the site most likely employs droop control, where frequency may take on a range of values in response to changes in load. The site may need to adjust droop control settings to maintain a tighter frequency band to improve service quality based on QAF definitions.

Greater frequency variations across meters are seen on a monthly basis. Because measured frequency should be the same at all meters within a site, these deviations could be caused by differences in the data logged at each meter over a period of a month. For example, data gaps caused by outages or communication systems resetting that only affect a portion of the meters during parts of the day may result in different meters averaging to slightly different monthly frequencies overall. It can also be seen that frequency tends to trend lower in the spring and early summer, particularly in the month of May. This correlates well with the earlier observation that PV generation is typically lower during these months in many African countries due to heavy rains. Reconfiguring inverter settings, introducing anchor loads that primarily consume energy during the day, or adding additional storage to shift PV production to nighttime hours may help to improve the frequency performance of this site.
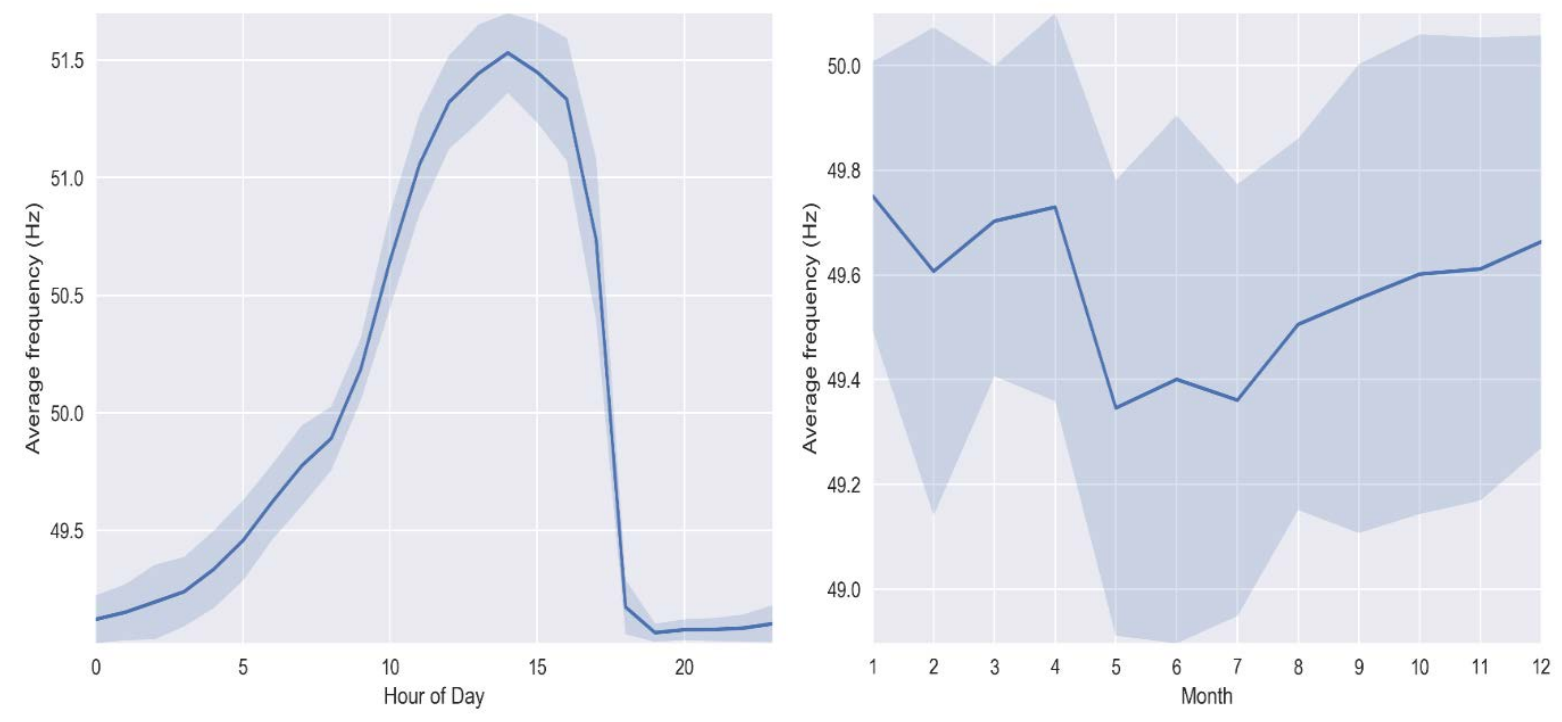

Figure 15. Average frequency profiles at Site 5

\subsubsection{Power Factor}

Power factor is a measurement of the ratio of real power to apparent power in an electrical network, conceptually a loss term if system loads exhibit a high level of inductance. The QAF does not have defined levels of performance for power factor as it can vary substantially between 0 and 1 depending on the types of loads in the system and the distribution network design.

Utility companies typically try to maintain power factor as close to 1 as possible as they are usually only able to bill customers for real power consumption even though both real and reactive power must be supplied (apparent power is composed of both real and reactive power). In more developed markets, utility companies charge customers extra fees if their loads result in a power factor of less than 0.8 .

In the current analysis, high variance was observed in power factor values across all 36 sites. To avoid the disproportionate impact of reactive loads on power factor when active power draw is very small 
(e.g., from unused chargers that are plugged into an outlet), the analysis of power factor statistics only considers power factor measurements when active power draw is greater than $10 \mathrm{~W}$. Figure 16 shows the distribution of power factor values for all meters across all sites filtered for when active power consumption is above $10 \mathrm{~W}$. Power factor values range from a minimum of 0.042 to a maximum of 1 , with a median value of 0.65 . No clear correlation was observed between power factor and location or the number of meters per site.

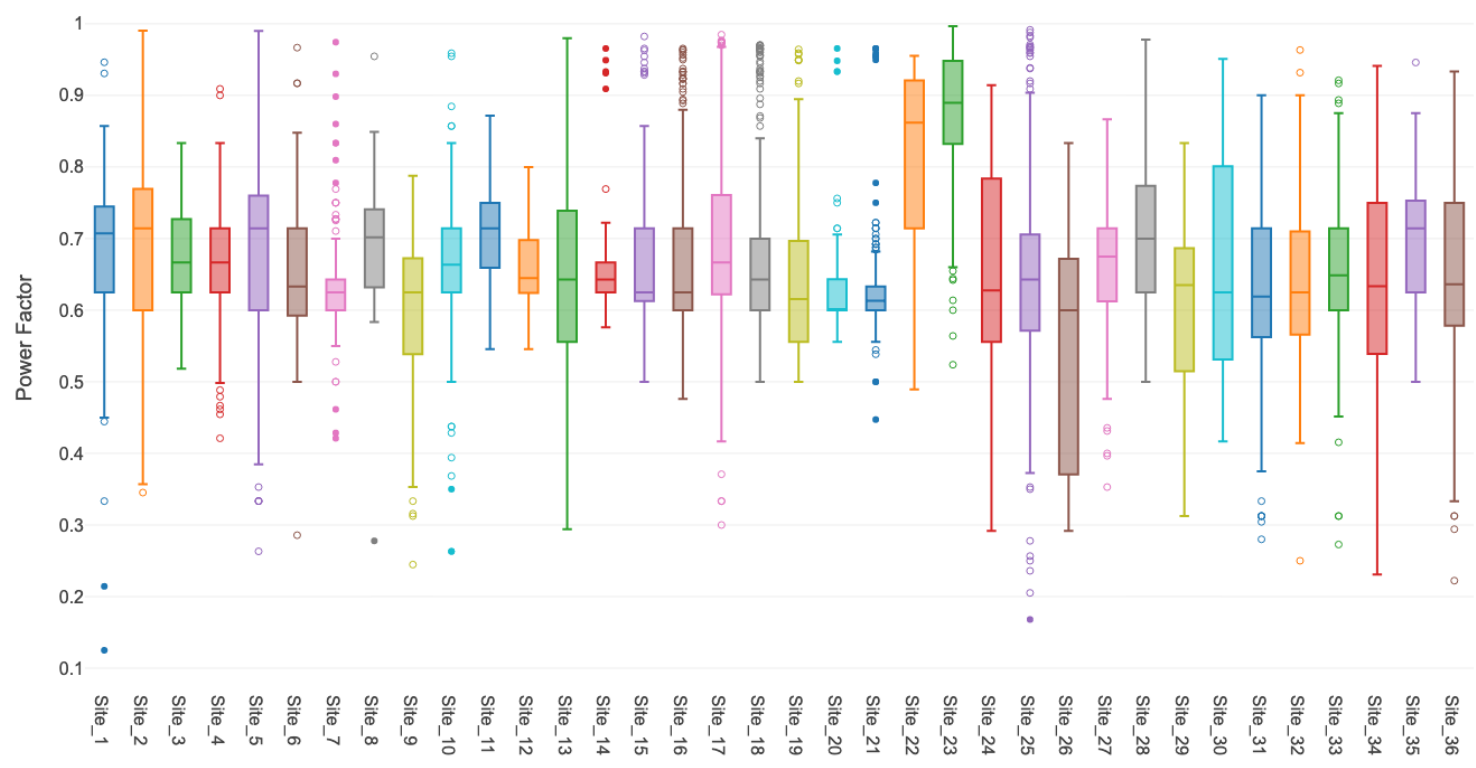

Figure 16. Distribution of power factor values across all the meters at each site

Potential causes for the prevalence of low power factor values across all sites in this data set vary but likely explanations include the presence of highly non-linear loads and the underestimation of reactive power demands. Non-linear loads such as variable frequency drives, the switch-mode power supply found in many power electronic devices today, and types of LED lighting, introduce harmonic distortions into the current waveform, resulting in lower power factors. At the same time, reactive power needs from large inductive or capacitive loads or the reactive power consumption of extensive distribution networks, may be underestimated.

Traditionally, reactive power is produced by the rotational inertia in generation systems, but many micro-grids today derive their reactive power supply from inverters. Inverters use an internal capacitor bank to produce reactive power, but supplying large amounts strains the system, leading to performance degradation and reduced equipment life. Typically, reactive power represents a system loss, meaning the power system must produce it while not receiving payment for its production. Micro-grid companies that are only billing customers for real power consumption may want to evaluate the reactive power loads on their systems and incorporate alternative billing mechanisms for loads that require high levels of reactive power support. Additionally, power factor compensators can be installed near specific loads to improve power factor locally.

An example of how performance monitoring data can be used to evaluate how different loads contribute to power factor issues in a system is presented in Figure 17. Average daily consumption and power factor data is plotted for each meter in Site 9 individually. Site 9 was chosen as its power factor distribution is typical of the median performance observed across all 36 sites.

The top plot in Figure 17 shows the typical daily power consumption profile at each of the 147 meters in the system. Profiles are sorted by color, with the lightest color representing customers with the lowest average power consumption and the dashed line representing the consumer with the highest average load. The bottom plot in Figure 17 shows the corresponding power factor profile for each load on the system, filtered for when active power draw is greater than $10 \mathrm{~W}$. While most profiles 
hover around an average power factor of 0.6 , the largest consumer has significantly worse power factor performance during parts of the day, with power factor values dropping below 0.3 from early to late afternoon. With this information, the site may consider installing power factor correction devices near this customer and restructuring its tariff schemes to charge for reactive power support. Continued performance monitoring of systems can help identify problems like this as they arise, so system operators can take corrective measures before overall system performance is affected and other customers are impacted.
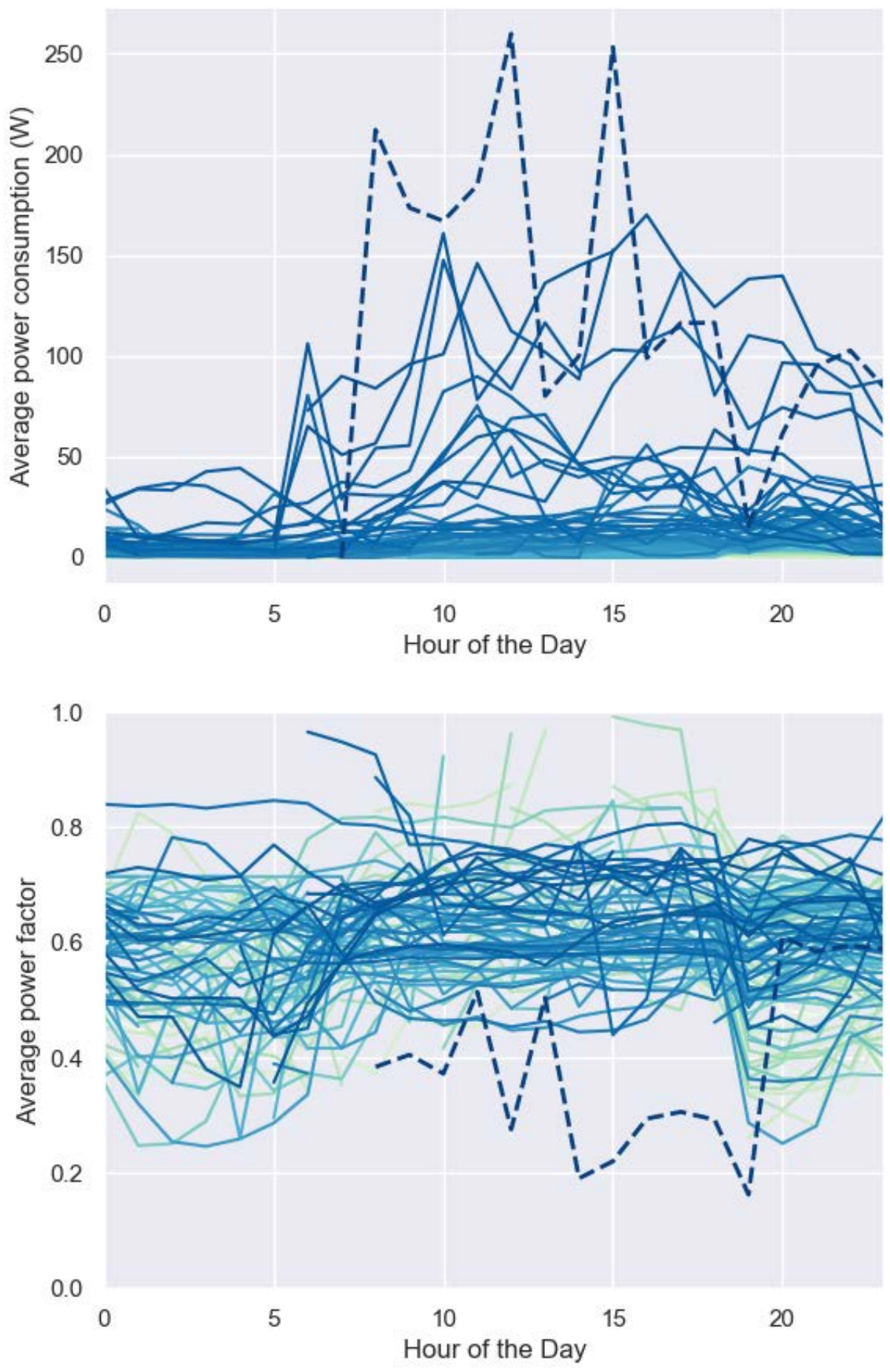

Figure 17. Average consumption and power factor profiles at Site 9 


\subsubsection{Power Availability and Consumption}

The QAF also establishes levels of service based on power availability or the amount of energy services provided to customers. Availability is characterized by maximum power draw limits, total energy supplied over a defined time period, and the duration of daily service. Because no information was available regarding the number of hours in a day power is available (periods during which customers are not consuming energy and planned/unplanned outages cannot be distinguished), we focus on categorizing meter performance according to the former two metrics in this analysis.

The QAF criteria for peak power service levels are given in Table 8, where higher service levels equate to greater power availability. Available power constrains the types of devices or equipment that can be used. In this analysis we distinguish between the level of service available to a customer, based on power draw limits defined by the system operator for each meter at each timestep, and the level of service actually used by the customer, based on actual measured consumption. A separate service level is assigned to each meter for power availability and power consumption using the maximum operator defined power draw limit and the actual maximum power draw registered at the meter over the provided data set respectively. It is noted that set load limits may not always translate directly to available power, so these results should be interpreted with caution.

Table 8. QAF Levels for Peak Power Draw

\begin{tabular}{ccc} 
LEVEL OF SERVICE & QAF LABEL & DEFINITION \\
\hline 1 & Level 1 & peak power $>3 \mathrm{~W}$ \\
\hline 2 & Level 2 & peak power $>50 \mathrm{~W}$ \\
\hline 3 & Level 3 & peak power $>200 \mathrm{~W}$ \\
\hline 4 & Level 4 & peak power $>800 \mathrm{~W}$ \\
\hline 5 & Level 5 & peak power $>2,000 \mathrm{~W}$ \\
\hline 6 & Level 6 & peak power $>5,000 \mathrm{~W}$
\end{tabular}

A similar set of definitions for energy service levels is also established in the QAF (Table 9). In this analysis, we based energy service level classifications on expected energy consumption in a typical year, assuming average consumption patterns in the available data repeat for periods with data gaps.

Table 9. QAF Levels for Energy Consumption

\begin{tabular}{ccc} 
LEVEL OF SERVICE & QAF LABEL & DEFINITION \\
\hline 1 & Level 1 & energy use $>4.38 \mathrm{kWh} / \mathrm{year}$ \\
\hline 2 & Level 2 & energy use $>73 \mathrm{kWh} / \mathrm{year}$ \\
\hline 3 & Level 3 & energy use $>365 \mathrm{kWh} / \mathrm{year}$ \\
\hline 4 & Level 4 & energy use $>1,250 \mathrm{kWh} / \mathrm{year}$ \\
\hline 5 & Level 5 & energy use $>3,000 \mathrm{kWh} / \mathrm{year}$ \\
\hline 6 & Level 6 & energy use $>73,000 \mathrm{kWh} / \mathrm{year}$ \\
\hline
\end{tabular}

Figure 18 shows the percentage of meters across all sites in each service level based on defined power limits and actual power and energy consumption. The results show a scenario of high potential for growth and low demand across all sites. Over $90 \%$ of meters have power limits in Service Level 3 or above, while more than $70 \%$ of meters show power consumption in Service Levels 1 and 2. Similarly, almost $85 \%$ of the total meters measured annual energy consumption at Service Levels 1 or 2 . It can 
also be noted that there is a greater percentage of customers at higher power consumption levels (Level 3 and above) compared to energy consumption levels. This could signify that while some consumers are acquiring larger appliances and higher power devices, the utilization of these remain low so energy consumption does not grow proportionally to power requirements.

Furthermore, this data shows that micro-grid operators generally set much higher power limits (largely Level 4) compared to what customers are consuming (largely Levels 1 and 2). It is possible that this indicates systems are overbuilt, with a greater ability to provide power than what is being consumed; however, the sum of all customer power limits is not a direct proxy for total power available, as the grid most likely cannot accommodate an overnight consumption increase up to the defined user limit across the entire customer base. Setting power limits is a balance between protecting against overconsumption and promoting growth so that customers who are ready to upgrade are not prevented from doing so.

Based on SparkMeter experience, grid operators in sub-Saharan Africa set more lenient power limits for low-usage customers to incentivize appliance purchase and higher levels of consumption and set power limits closer to actual consumption requirements for larger consumers or productive use customers who individually have larger impacts on the grid. System operators can use performance monitoring data to analyze their risk exposure and ensure the grid is not oversubscribed or initially too overbuilt. It is also worth noting that energy consumption typically increases over time, and since this data is generally from relatively new power systems, consumption would be expected to increase. Understanding the timing of this expected load growth, however, may allow power providers to more optimally design systems initially, with the ability to expand as power needs grew, reducing upfront costs to consumers and investors.

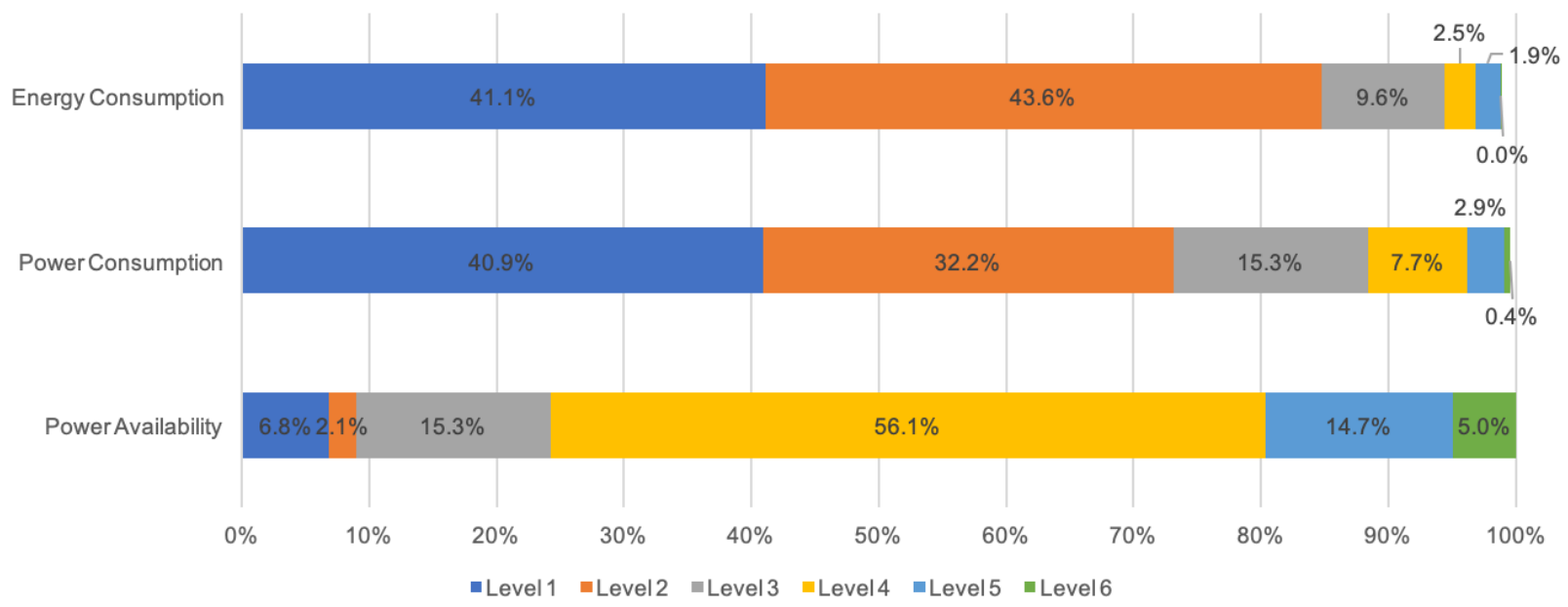

Figure 18. Distribution of meters in QAF service levels for power and energy performance

Load data can also be used to study typical consumption patterns. Understanding the frequency of occurrence of certain types of load profiles, along with their associated characteristics, such as when system peaks are expected to occur, average energy consumption levels, and load growth trends, can help inform system design and operation decisions and improve the accuracy of demand forecasting. Performance statistics can be correlated to different load profile shapes, so developers can have a better understanding of the types of challenges and special considerations that may be associated with a site based on the connected customer types.

The 36 sites studied in this analysis were classified into four general daily consumption pattern profiles similar to those identified in a previous SparkMeter analysis (Schnitzer 2017). These profiles are shown in Figure 19 and described below: 
- "Morning and Evening Peaks" - Sites exhibit a small morning peak around 6 a.m. and a large evening peak around 8 p.m., with low consumption during daytime hours. Consumption under this profile aligns the worst with the hours of PV generation.

- "Daytime Bump" - Sites have high consumption during the day, tapering off slightly in the late afternoon before peaking again in the evening around 8 or 9 p.m.

- "Daytime Baseload" - Sites have a consistent and steady rise in load throughout the day and peak in the evening around 8 or 9 p.m. Daytime loads are not quite as high as those expected in the Daytime Bump profiles.

- "Mostly Daytime" - These sites consume the most energy during the day, starting around 6 or 7 a.m. and taper off in the evening for low levels of consumption throughout the night. Consumption under this profile aligns the best with generation from PV systems.

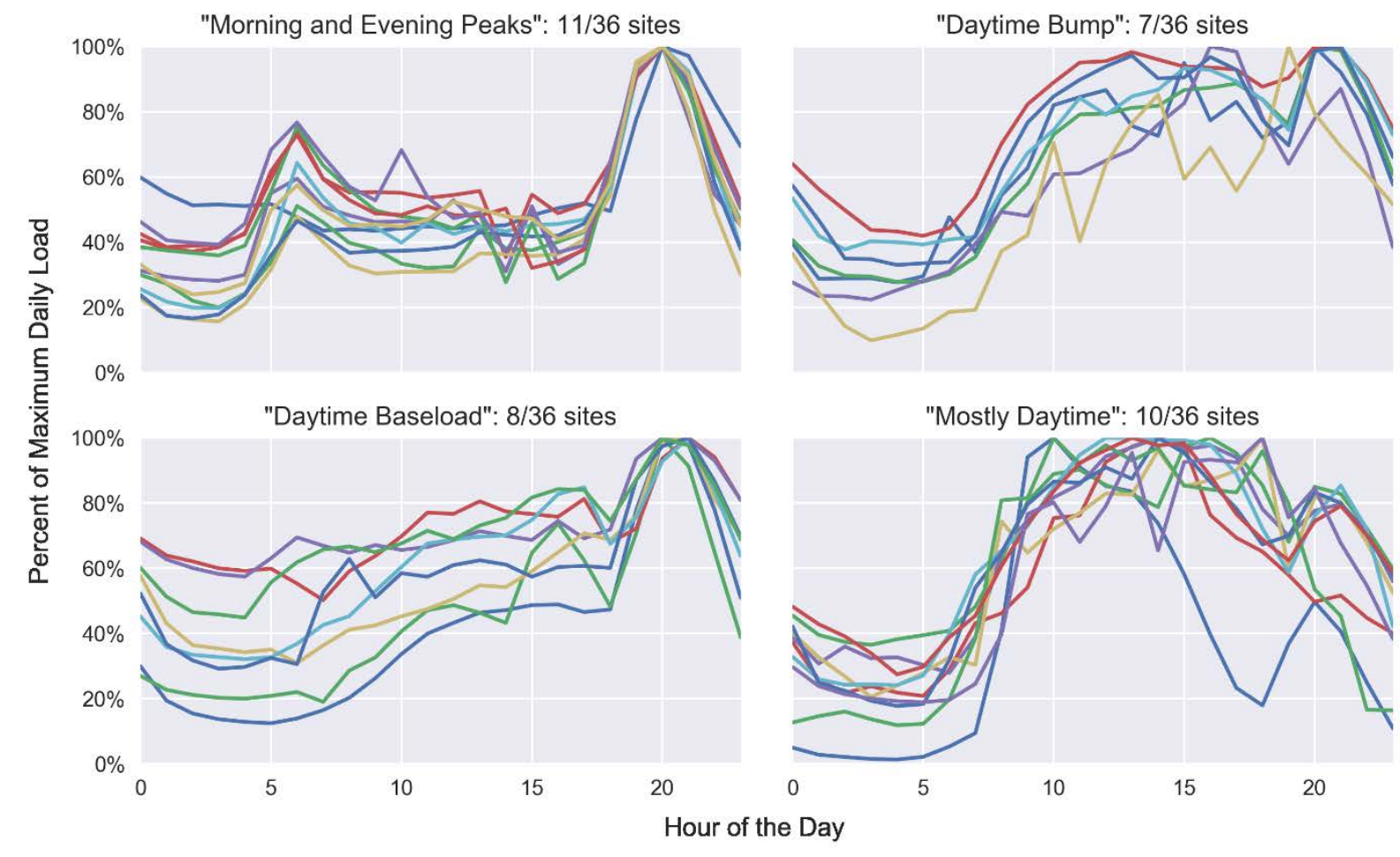

Figure 19. Average site load profiles classified into load shape groups

\subsubsection{Financial and Tariff Data}

Insights into financial and tariff data can also be garnered from smart meters. For example, SparkMeter previously found that the average monthly revenue per micro-grid customer per site was about \$5 USD per month (Schnitzer 2017); however, this average is skewed upward by the presence of several large customers; average revenues from a medium-sized customer is closer to \$2 USD per month, typically paid in biweekly increments of \$1 USD.

Meter data in the current analysis also yield insights on tariffs. While exact electricity rates are proprietary information, the range of tariff values observed were similar to other sub-Saharan Africa micro-grid systems, which were determined to be between $\$ 0.50 \mathrm{USD} / \mathrm{kWh}$ and $\$ 2.00 \mathrm{USD} / \mathrm{kWh}$, with a median of about $\$ 0.90 \mathrm{USD} / \mathrm{kWh}$, in a previous analysis (Booth 2018).

Trends in how the cost of electricity changes by average consumption level, time of day, and season can also be analyzed using the data. Site 29 is presented as an example in Figure 20. The top plot shows how average electricity rates vary for customers of different average consumption levels. Generally, per kWh costs decrease as average load increases. Larger customers with more predictable demand can increase grid stability and provide a more consistent source of project income if they 
have a reliable payment history. As a result, power is often provided to them at lower costs. The middle plot shows tariffs across the system over an average 24-hour period, with the shaded area representing the standard deviation of the rates across all meters. Rates tend to be lowest during daytime hours, coinciding with the hours of PV production. Finally, the bottom plot shows seasonal rate variations, with the lowest rates seen in late summer and early fall.

Developers can use performance monitoring data to track expected/actual revenues and monitor customer groups to ensure they are on an appropriate rate tariff as consumption levels and patterns change. Aggregated views of the impacts of different time-of-use tariffs can also help inform tariff design decisions, making sure the cost of electricity reflects the changing cost of electricity supply. 

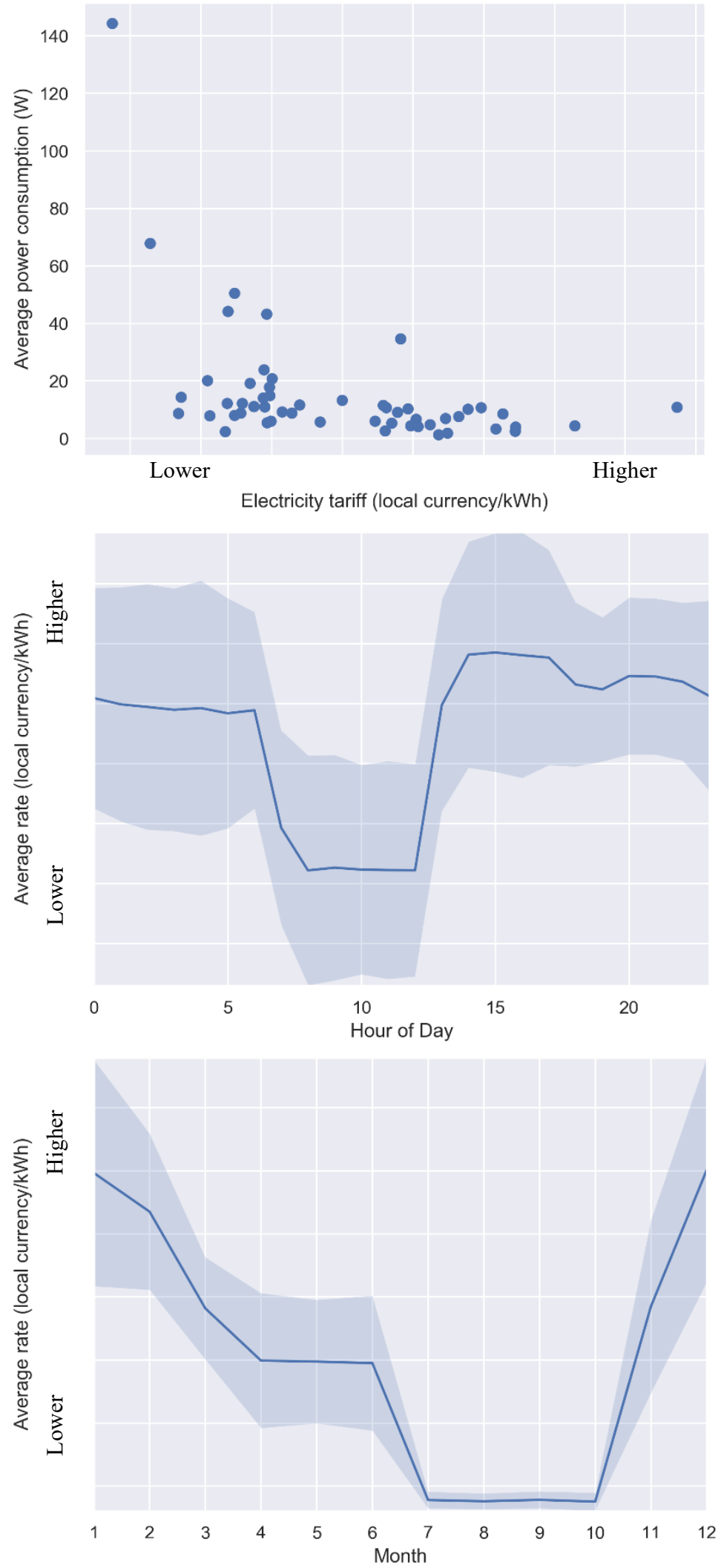

Figure 20. Changes in electricity cost by average consumption, time of day, and season

(The exact cost data has been removed from this figure to maintain confidentiality.) 


\subsection{SparkMeter Data Analysis Conclusions}

Some key takeaways regarding overall micro-grid performance in sub-Saharan African countries from the analysis of the SparkMeter data set are presented below:

- Voltage and frequency performance levels are high for most systems during most hours of operation; however, a small fraction of measurements show performance outside of the bounds of safe operation, risking customer safety and damage to equipment and the overall power system. Steps should be taken to identify causes and solutions at sites with the most significant issues.

- Comparatively low power factor values were identified as an issue across all sites. Reactive power compensation for power factor correction is particularly challenging in low-inertia renewable energy systems. The selection and sizing of inverters in future systems will be critical. Developers should continually monitor reactive power loads on their systems to catch problems as they arise. They may also consider implementing advanced inverter functionalities and/or new billing mechanisms for reactive power consumption.

- Operator-defined user power limits are significantly higher than measured consumption at most sites, possibly indicating that systems are overbuilt; however, energy usage data gathered through the performance monitoring process can be used to garner insights into typical consumption patterns, leading to improved demand modeling and load growth forecasting in the future.

- Classifying customer consumption patterns can also help with tariff design. Time-of-use rates or reduced tariffs can be employed to incentivize desired load profiles. Developers can use performance monitoring data to ensure customer groups are on an appropriate rate tariff based on their consumption patterns and track expected versus actual revenues.

Several ways of using performance monitoring data to identify problems and potential causes to better understand and improve the operation of micro-grids in sub-Saharan Africa have been presented in this section. These are just a few examples of what can be done when performance monitoring data is available. In the future, metered data can be paired with system operator data to gain further insights into strategies for optimizing system design and operations and reducing maintenance costs and challenges. For example, customers with high current draws or periods during which several customers have high current draws can be analyzed to predict when inverters may trip or when equipment may fail, allowing grid operators to plan for the necessary types of corrective actions. This can lead to fewer unplanned technical site visits and longer equipment life, reducing overall O\&M costs. Consistent monitoring and analysis can help improve system performance, increase customer satisfaction, attract more investment, and generally work to reduce risks in the micro-grid sector. 


\section{Challenges, Lessons, and Recommendations}

This section presents the common challenges and lessons from working with developers in support of performance monitoring along with the key recommendations from this report.

\subsection{Challenges and Lessons From Collecting and Analyzing Data}

A huge variation exists in the ability of micro-grid developers to collect and analyze data associated with the operation of a micro-grid. This is largely dependent on experience and financial and human resources. Many of the key issues related to capabilities and resources are interrelated, so improvements made in any one area can have significant positive effects on the others. A few key issues and lessons learned are discussed below.

Planning: Many developers fail to plan for the collection and analysis of data when designing or implementing a project. This can create significant issues when data needs are identified, but the tools and processes needed to collect or analyze the data do not exist, which in turn increases the resources required. E4I has often been approached by developers experiencing technical issues, but the basic data required to diagnose the issues were not readily or easily available. Data collection and analysis should be considered by all developers from the earliest stage of a project, incorporating lessons learned from previous projects.

Conflicting data: This issue is especially prevalent for larger developers, where more than one team may be collecting or analyzing data. For example, E4I worked with a developer that had three different figures for the monthly expenditure of a micro-grid project. To make informed decisions, it is vital that only one version of the truth exists. This can be accomplished by defining specific staff and team roles in the data collection process and having one organization-wide approach to data analysis.

Connecting data sets: Data becomes most valuable when it is analyzed in conjunction with other similar or connected data sets. Many developers fail to link technical data with commercial or customer data. In one example, E4I analyzed customer feedback on power reliability and determined that the technical team was not able to record all system outages accurately. E4I supported the developer in improving the classification of different data sets and data distribution mechanisms to maximize the effectiveness of the collected data.

Redundant or irrelevant data: Irrelevant data is data that is collected but serves no purpose. Redundant data is data that has been collected in more than one way. Collection of these data types adds cost without any benefit to the developer. By performing regular data audits as part of the performance monitoring process, these data streams can be removed, and resources saved. It should be noted, however, that given the cost in time and funds to repair or troubleshoot sensors, some level of redundancy may be useful or even cost effective. Furthermore, data thought to be irrelevant for current analysis efforts may become useful as projects develop and portfolios grow. Having a history of certain data streams may become valuable to developers, so decisions about what data to collect should be made carefully during the planning stages of a project.

Lack of responsibility: The decision-making process of developers is often slow due to a lack of defined roles, delaying the rectification of issues. In one example, E4I worked with a developer experiencing significant technical challenges that were increasing operating costs. It was found that while the developer had a robust data collection and analysis methodology in place, no actions were being taken to rectify the issues. One major cause of this was that no team had been assigned the responsibility of implementing the identified performance improvement activities. E4I supported the developer in defining the roles and responsibilities of teams tasked with implementing changes and set up the approval mechanisms required to do so. This resulted in swifter implementation of performance improvement activities, showing the importance of defining roles, assigning responsibility and accountability, and following through with the full performance monitoring cycle. 


\subsection{Recommendations}

The key recommendations of this report for integrating performance monitoring into the micro-grid sector are presented below:

Creation, dissemination, and adoption of a standardized performance monitoring guide and framework for the micro-grid sector: Through desktop research, meetings with developers, and workshops with developers and stakeholders, it is clear that there is no standardized approach for performance monitoring within the micro-grid sector and that knowledge and information on performance monitoring is limited. This report has outlined a general performance monitoring process that could be implemented within the micro-grid sector, as well as key activities that would benefit from the adoption of a performance monitoring process. It is recommended that this is built upon to create a standardized approach to performance monitoring that can then be used across the industry and across countries. This should be developed in conjunction with developers and be country and technology agnostic. An initial conceptual framework, building off the QAF, has been developed by TFE Energy and is expected to be deployed in Nigeria and potentially other African nations. Details of this framework can be found in Appendix B.

Training for micro-grid developers on performance monitoring: The limited knowledge on performance monitoring indicates that the development and dissemination of a standardized guide will not be sufficient to embed performance monitoring within the sector. It is therefore recommended that guides be accompanied by training for developers in performance monitoring. This could either be conducted through technical assistance engagements with individual developers or training workshops and events.

Sharing of performance indicators and data across the industry: Performance monitoring is most powerful when large and long-term data sets are available from which findings can be drawn. Access to a large data set is especially important at the project planning and development stage (e.g., for demand assessments). Currently within the micro-grid sector, there is limited sharing of data, which is preventing performance monitoring from being used to its fullest potential. Therefore, it is recommended that data is shared across the industry to improve knowledge sharing and the overall effectiveness of performance monitoring. This would require the identification of a central stakeholder in the industry, such as the African Mini-grid Developers Association (AMDA), to be the holder of such data and responsible for its use.

Increase developer awareness of equipment and tools used for performance monitoring: The desktop research and workshops identified that developers have limited knowledge of the equipment available to them for collecting data. This has resulted in data collection being a time and resource intensive activity. It is recommended that a database of the equipment available on the market is built to support developers during the planning and development stage of a project.

Currently operating micro-grids typically maintain high levels of performance, but sporadic power quality issues must be addressed: Analysis of SparkMeter data of 36 micro-grids in Africa showed that most systems are operating at a high-performance level considering a variety of power quality metrics; however, a small fraction of measurements is outside of the bounds of safe operation, risking customer safety and damage to equipment. Further performance monitoring should be undertaken to identify causes and solutions to these power quality issues. 


\section{References}

AMMP Technologies. "Reducing the cost of operations and maintenance for remote off-grid energy systems." September 2018. https://www.ammp.io/remote-monitoring-cost-reduction/.

Baring-Gould, Ian, Kari Burman, Mohit Singh, Sean Esterly, Rose Mutiso, and Caroline McGregor. Quality Assurance Framework for Mini-Grids. Golden, CO: National Renewable Energy Laboratory. NREL/TP-5000-67374. November 2016. https://www.nrel.gov/docs/fy17osti/67374.pdf.

Baring-Gould, Ian, Sean Esterly, Kari Burman, and Chris Greacen. Quality Assurance Framework Implementation Guide for Isolated Community Power Systems. Golden, CO: National Renewable Energy Laboratory. NREL/TP-7A40-68634. August 2017. https://www.nrel.gov/docs/fy17osti/68634.pdf.

Blodgett, Courtney, Peter Dauenhauer, Henry Louie, and Lauren Kickham. "Accuracy of Energy-Use Surveys in Predicting Rural Mini-Grid User Consumption.” Energy for Sustainable Development 41 (December 2017): 88-105. https://www.sciencedirect.com/science/article/pii/S0973082617304350.

Booth, Samuel,_Xiangkun Li, Ian Baring-Gould, Diana Kollanyi, Abishek Bharadwaj, and Peter Weston. Productive Use of Energy in African Microgrids: Technical and Business Considerations. Golden, CO: National Renewable Energy Laboratory. NREL/TP-7A4071663. August 2018. https://www.nrel.gov/docs/fy18osti/71663.pdf.

Dipendra Bhattarai, Drew Corbyn, Zibusiso Ncube, Elizabeth Njoki, and Louise Waters. Real-time Monitoring, Control and Payment Technologies for Mini-grids. Practical Action Consulting. June 2016. https://infohub.practicalaction.org/bitstream/handle/11283/620306/Introduction\%20for\%20Pr actitioners.pdf;jsessionid=82404D453A1746D145084C0F7C7B5EB1? sequence=1.

IEA (International Energy Agency). "Energy Access Outlook 2017: From Poverty to Prosperity." Paris, France: IEA. October 2017. http://www.iea.org/access2017/.

IEA. "IEA Workshop on Energy for all: Financing access for the poor." Paris, France: International Energy Agency. May 2011. https://www.iea.org/events/iea-workshop-on-energy-for-allfinancing-access-for-the-poor.

Schnitzer, Daniel. "What smart metering data says about microgrid trends from sites deployed with SparkMeter Systems." Presented at HOMER Microgrid Conference, Denver, CO. September 18-19, 2017.

World Bank Group. "Climate Change Knowledge Portal: Kenya Historical Climate Data." Washington, D.C.: World Bank Group. 2019.

https://climateknowledgeportal.worldbank.org/country/kenya/climate-data-historical 


\section{Appendix A. Data Collection Methodology and Advice}

A standardized data collection methodology should be developed across projects and programs to maintain consistency regardless of when or by whom data is collected. This is crucial to accurately assess a project or program's performance and the impact of any changes that are made. The defined methodology will also form the basis of training programs, as well as inform the types of equipment and resources needed for the data collection process.

The data collection methodology should be fully documented, including the instruments and the level of accuracy required for different data types. Training materials should be developed to ensure that all those involved in the collection of data are able to do so to the standard required.

The data collection methodology should also include contingency plans for what to do if specific information related to each of the key indicators cannot be collected. This could include specifying how and how often manual measurements should be taken or how specific parties should be notified in the event of a data collection system failure.

An example documentation structure is presented in Table A- 1.

Table A- 1. Example Performance Monitoring Documentation Structure

\begin{tabular}{|l|l|l|l|l|l|l|}
\hline GOAL & INDICATOR & DATA & $\begin{array}{l}\text { COLLECTION } \\
\text { METHODOLOGY }\end{array}$ & $\begin{array}{l}\text { DATA } \\
\text { ANALYSIS }\end{array}$ & REPORTING & COMMENTS \\
\hline \multirow{2}{*}{ Goal 1 } & Indicator 1 & Indicator 1: Data A & $\begin{array}{l}\text { Data A: Collection } \\
\text { methodology }\end{array}$ & $\begin{array}{l}\text { Data } \\
\text { analysis } \\
\text { comments }\end{array}$ & $\begin{array}{l}\text { Reporting } \\
\text { requirements: } \\
\text { Frequency } \\
\text { and } \\
\text { distribution }\end{array}$ & Comments \\
\cline { 2 - 5 } & Indicator 1: Data B & $\begin{array}{l}\text { Data B: Collection } \\
\text { Methodology }\end{array}$ & $\begin{array}{l}\text { Data C: Collection } \\
\text { methodology }\end{array}$ & \\
\hline \multirow{2}{*}{ Goal 2 } & Indicator 1 & Etc. & & & \\
\hline
\end{tabular}

\section{Key Advice: Data Collection}

- Follow the defined data collection methodology that has been determined for the process.

- Document challenges experienced when collecting data so that the data collection methodology can be refined. This could include how the data is collected (e.g., manual vs. automated), when it is collected (e.g., frequency of collection), and who collects the data (e.g., is the member of staff appropriately trained?).

- Be consistent with data entry. The data collection methodology should be precise in defining the data and how it is collected. It is vital that the data collected is consistent with this to ensure its validity.

- Do not guess or approximate data. This is especially important when collecting data from stakeholders (e.g., through surveys). Be persistent in obtaining the information required, and do not resort to assumptions or asking leading questions. Otherwise, the data can become biased.

- When collecting data on paper, the data should be entered as a soft copy (e.g., into Excel) daily to ensure timely collection and to avoid the potential loss of data.

- Check the data post collection and question the data that has been collected. The point of collection of data is the first opportunity to assess data quality. If there are obvious errors in the collected data, it should either be collected again, or a note should be made that it contains errors. 
- When verifying the data, errors may be instantly recognizable; for example, an outlier by an order of magnitude where the data recorder has accidently added an extra digit. Document anywhere you believe a mistake has been made and check these with the data collector. If similar errors occur commonly in the data sets, then the data collection methodology will need to be refined.

- Data analysis and visualization techniques will likely need refinement and testing prior to fullscale implementation and use to reduce time and redundancy and to aid in easy visualization.

- Data should only be distributed to stakeholders identified in the process, as some of the collected data may contain confidential or sensitive information. If a stakeholder wishes to share information, then the data owner should be consulted.

- The performance monitoring process is cyclical, meaning the evaluation step, along with all the other steps, should be carried out more than once. Evaluated data may not initially show any obvious trends but when seen as a part of the bigger picture, trends may become obvious.

- All recommendations should be documented, fully defined, and prioritized for implementation. An implementation plan should be developed to ensure that recommendations are implemented properly. 


\title{
Appendix B. Adapted QAF Metrics for Performance Monitoring in Nigeria
}

\author{
Table B- 1. TFE Energy's Adaptation of the QAF into Performance Monitoring Metrics
}

(The full set of desired metrics is listed below with the minimum parameters required shown in red.)

\begin{tabular}{|c|c|c|c|c|c|c|c|}
\hline & \multirow[t]{2}{*}{ METRIC } & \multirow[t]{2}{*}{ DETAILS OF METRIC } & \multicolumn{2}{|c|}{$\begin{array}{l}\text { SUGGESTED } \\
\text { REPORTING } \\
\text { FREQUENCY }\end{array}$} & \multirow[t]{2}{*}{$\begin{array}{l}\text { DATA } \\
\text { LEVEL }\end{array}$} & \multirow[t]{2}{*}{$\begin{array}{l}\text { POSSIBLE } \\
\text { SOURCE }\end{array}$} & \multirow{2}{*}{$\begin{array}{l}\text { STAGE IN } \\
\text { PROJECT LIFE } \\
\text { CYCLE }\end{array}$} \\
\hline & & & AUTO & MANUAL & & & \\
\hline \multirow{24}{*}{ 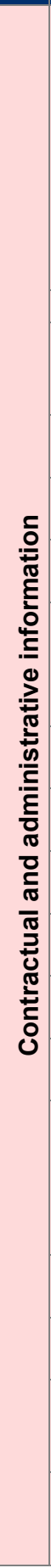 } & \multirow{7}{*}{$\begin{array}{l}\text { General company-wide } \\
\text { information }\end{array}$} & Company name & & \multirow{7}{*}{ As needed } & \multirow{7}{*}{ Portfolio } & \multirow{7}{*}{ Web Form } & \multirow{7}{*}{$\begin{array}{l}\text { Registration/permit } \\
\text { application }\end{array}$} \\
\hline & & Physical address & & & & & \\
\hline & & Postal address & & & & & \\
\hline & & Tel, fax, cell numbers & & & & & \\
\hline & & Email and website & & & & & \\
\hline & & $\begin{array}{l}\text { Description of main } \\
\text { business activities }\end{array}$ & & & & & \\
\hline & & $\begin{array}{l}\text { Name of contact } \\
\text { person }\end{array}$ & & & & & \\
\hline & Name of micro-grid site & & & As needed & Site & Web Form & Permit application \\
\hline & $\begin{array}{l}\text { Name of state, local government, } \\
\text { ward and village where micro-grid } \\
\text { is located }\end{array}$ & & & As needed & Site & Web Form & $\begin{array}{l}\text { Registration/permit } \\
\text { application }\end{array}$ \\
\hline & $\begin{array}{l}\text { Geographical coordinates of } \\
\text { micro-grid }\end{array}$ & & & As needed & Site & Web Form & $\begin{array}{l}\text { Registration/permit } \\
\text { application }\end{array}$ \\
\hline & System commissioning reports & & & $\begin{array}{l}\text { Annually or } \\
\text { as needed }\end{array}$ & Portfolio & $\begin{array}{l}\text { Uploaded } \\
\text { document }\end{array}$ & Commissioning \\
\hline & Legal status of operator & & & $\begin{array}{l}\text { Annually or } \\
\text { as needed }\end{array}$ & Portfolio & Check box & $\begin{array}{l}\text { Registration/permit } \\
\text { application }\end{array}$ \\
\hline & $\begin{array}{l}\text { Certified copies of certificate of } \\
\text { incorporation, memorandum and } \\
\text { articles of association, deed of } \\
\text { partnership or deed of trust }\end{array}$ & & & $\begin{array}{l}\text { Annually or } \\
\text { as needed }\end{array}$ & Portfolio & $\begin{array}{l}\text { Uploaded } \\
\text { document }\end{array}$ & Permit application \\
\hline & $\begin{array}{l}\text { Certified copy of certificate of } \\
\text { occupancy or lease agreement }\end{array}$ & & & $\begin{array}{l}\text { Annually or } \\
\text { as needed }\end{array}$ & Site & $\begin{array}{l}\text { Uploaded } \\
\text { document }\end{array}$ & Permit application \\
\hline & Certified copy of building permit & & & $\begin{array}{l}\text { Annually or } \\
\text { as needed }\end{array}$ & Site & $\begin{array}{l}\text { Uploaded } \\
\text { document }\end{array}$ & Permit application \\
\hline & Signed health and safety form & & & $\begin{array}{l}\text { Annually or } \\
\text { as needed }\end{array}$ & Site & $\begin{array}{l}\text { Uploaded } \\
\text { document }\end{array}$ & Permit application \\
\hline & Standard rate schedules (tariffs) & & & $\begin{array}{l}\text { Annually or } \\
\text { as needed }\end{array}$ & Portfolio & $\begin{array}{l}\text { Uploaded } \\
\text { document }\end{array}$ & $\begin{array}{l}\text { Registration/permit } \\
\text { application }\end{array}$ \\
\hline & $\begin{array}{l}\text { Filled standardized spreadsheets } \\
\text { for tariff calculation }\end{array}$ & & & $\begin{array}{l}\text { Annually or } \\
\text { as needed }\end{array}$ & Site & $\begin{array}{l}\text { Uploaded } \\
\text { document }\end{array}$ & Permit application \\
\hline & $\begin{array}{l}\text { Contract with community } \\
\text { representative }\end{array}$ & & & $\begin{array}{l}\text { Annually or } \\
\text { as needed }\end{array}$ & Site & $\begin{array}{l}\text { Uploaded } \\
\text { document }\end{array}$ & Permit application \\
\hline & User contract & & & $\begin{array}{l}\text { Annually or } \\
\text { as needed }\end{array}$ & Portfolio & $\begin{array}{l}\text { Uploaded } \\
\text { document }\end{array}$ & $\begin{array}{l}\text { Permit application } \\
\text { and during } \\
\text { operations phase } \\
\text { as new users sign } \\
\text { up }\end{array}$ \\
\hline & $\begin{array}{l}\text { Daily hours of service to be } \\
\text { delivered }\end{array}$ & & & $\begin{array}{l}\text { Annually or } \\
\text { as needed }\end{array}$ & Site & Web Form & Permit application \\
\hline & $\begin{array}{l}\text { Expected electricity sales } \\
\text { (kWh/year) }\end{array}$ & & & $\begin{array}{l}\text { Annually or } \\
\text { as needed }\end{array}$ & Site & Web Form & $\begin{array}{l}\text { Registration/permit } \\
\text { application }\end{array}$ \\
\hline & $\begin{array}{l}\text { Payment processes (e.g., mobile } \\
\text { money, tokens, agents) }\end{array}$ & & & $\begin{array}{l}\text { Annually or } \\
\text { as needed }\end{array}$ & Portfolio & $\begin{array}{l}\text { Check box } \\
\text { and } \\
\text { description }\end{array}$ & Permit application \\
\hline & $\begin{array}{l}\text { Compliance with applicable } \\
\text { standards and regulations }\end{array}$ & & & $\begin{array}{l}\text { Annually or } \\
\text { as needed }\end{array}$ & Portfolio & $\begin{array}{l}\text { Uploaded } \\
\text { document }\end{array}$ & $\begin{array}{l}\text { Registration/permit } \\
\text { application and } \\
\text { during operations }\end{array}$ \\
\hline
\end{tabular}




\begin{tabular}{|c|c|c|c|c|c|c|c|}
\hline & $\begin{array}{l}\text { Contact details of customer } \\
\text { complaints unit }\end{array}$ & & & $\begin{array}{l}\text { Annually or } \\
\text { as needed }\end{array}$ & $\begin{array}{l}\text { Portfolio } \\
\text { /site }\end{array}$ & Web Form & $\begin{array}{l}\text { Registration/permit } \\
\text { application and } \\
\text { during }\end{array}$ \\
\hline & $\begin{array}{l}\text { Person responsible for customer } \\
\text { complaints unit }\end{array}$ & & & $\begin{array}{l}\text { Annually or } \\
\text { as needed }\end{array}$ & $\begin{array}{l}\text { Portfolio } \\
\text { /site }\end{array}$ & Web Form & $\begin{array}{l}\text { Registration/permit } \\
\text { application and } \\
\text { during operations }\end{array}$ \\
\hline & Customer complaints procedure & & & $\begin{array}{l}\text { Annually or } \\
\text { as needed }\end{array}$ & Portfolio & $\begin{array}{l}\text { Check box } \\
\text { and } \\
\text { description }\end{array}$ & Commissioning \\
\hline & Proof of customer training delivery & & & $\begin{array}{l}\text { Annually or } \\
\text { as needed }\end{array}$ & Site & $\begin{array}{l}\text { Uploaded } \\
\text { document }\end{array}$ & Commissioning \\
\hline & $\begin{array}{l}\text { Details of Community Power } \\
\text { Committee }\end{array}$ & $\begin{array}{l}\text { Names and contact } \\
\text { details of members }\end{array}$ & & $\begin{array}{l}\text { Annually or } \\
\text { as needed }\end{array}$ & Site & Web Form & $\begin{array}{l}\text { Commissioning } \\
\text { and during } \\
\text { operations }\end{array}$ \\
\hline & Total number of customers (\#) & & $\mathrm{x}$ & & & Calculated & \\
\hline & & $\begin{array}{l}\text { Residential customers } \\
\text { (\#) }\end{array}$ & $\mathrm{x}$ & & & Web Form & Registration/permit \\
\hline 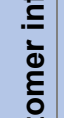 & Customers by sector & $\begin{array}{l}\text { Commercial } \\
\text { customers, one-phase } \\
\text { (\#) }\end{array}$ & $\mathrm{x}$ & $\begin{array}{l}\text { Annually or } \\
\text { as needed }\end{array}$ & Site & Web Form & $\begin{array}{l}\text { application } \\
\text { (expected } \\
\text { numbers) and }\end{array}$ \\
\hline 足 & & Public customers (\#) & $\mathrm{x}$ & & & Web Form & actual numbers in \\
\hline & & $\begin{array}{l}\text { Productive customers, } \\
\text { three-phase (\#) }\end{array}$ & $\mathrm{x}$ & & & Web Form & operations phase \\
\hline & & Anchor customers (\#) & $x$ & & & Web Form & \\
\hline & & $\begin{array}{l}\text { Total installed capacity } \\
\text { (kW) }\end{array}$ & $\mathrm{x}$ & & & & \\
\hline & & PV peak $(\mathrm{kW})$ & & & & & \\
\hline & & Genset capacity (kW) & & & & & \\
\hline & & $\begin{array}{l}\text { Other generation (kW) } \\
\text { (specify) }\end{array}$ & & & & & \\
\hline & & Battery storage (kW) & & & & & \\
\hline & & Inverter capacity $(\mathrm{kW})$ & & & & & \\
\hline & & $\begin{array}{l}\text { Total distribution } \\
\text { infrastructure }(\mathrm{m}) \text { and } \\
\text { coordinates of four } \\
\text { reference points }\end{array}$ & & & & & \\
\hline & Installed canacity & Single-phase MV (m) & & Annually or & Site & Web Form & Registration/permit \\
\hline & & Three-phase MV (m) & & as needed & & & $\begin{array}{l}\text { application and in } \\
\text { operations phase }\end{array}$ \\
\hline & & Single-phase LV $(\mathrm{m})$ & & & & & in the case of \\
\hline & & Three-phase LV (m) & & & & & changes \\
\hline 总 & & $\begin{array}{l}\text { Type of distribution } \\
\text { (overhead, } \\
\text { underground) }\end{array}$ & & & & & \\
\hline $\begin{array}{l}\frac{5}{0} \\
0 \\
0 \\
0 \\
0 \\
0\end{array}$ & & $\begin{array}{l}\text { Type and number of } \\
\text { poles (e.g., cement, } \\
\text { wood) }\end{array}$ & & & & & \\
\hline$\frac{0}{2}$ & & $\begin{array}{l}\text { Rating of transformers } \\
(\mathrm{kW})\end{array}$ & & & & & \\
\hline & & $\begin{array}{l}\text { Total number of } \\
\text { transformers }\end{array}$ & & & & & \\
\hline & Total CAPEX (\$) & & & $\begin{array}{l}\text { Annually or } \\
\text { as needed }\end{array}$ & Site & Calculated & \\
\hline & & $\begin{array}{l}\text { CAPEX spent on } \\
\text { distribution }(\$)\end{array}$ & & & & & \\
\hline & & $\begin{array}{l}\text { CAPEX spent on PV } \\
\text { generation (\$) }\end{array}$ & & & & & Commissioning \\
\hline & Detailed CAPFX & $\begin{array}{l}\text { CAPEX spent on other } \\
\text { RE generation (\$) }\end{array}$ & & Annually or & Site & Woh Form & $\begin{array}{l}\text { and during } \\
\text { operations phase }\end{array}$ \\
\hline & Detalled CAPEX & $\begin{array}{l}\text { CAPEX spent on } \\
\text { storage }(\$)\end{array}$ & & as needed & Site & Web Form & $\begin{array}{l}\text { in the case of } \\
\text { changes/additions }\end{array}$ \\
\hline & & $\begin{array}{l}\text { CAPEX spent on } \\
\text { gensets }(\$)\end{array}$ & & & & & to the system \\
\hline & & $\begin{array}{l}\text { CAPEX spent on } \\
\text { metering }(\$)\end{array}$ & & & & & \\
\hline
\end{tabular}




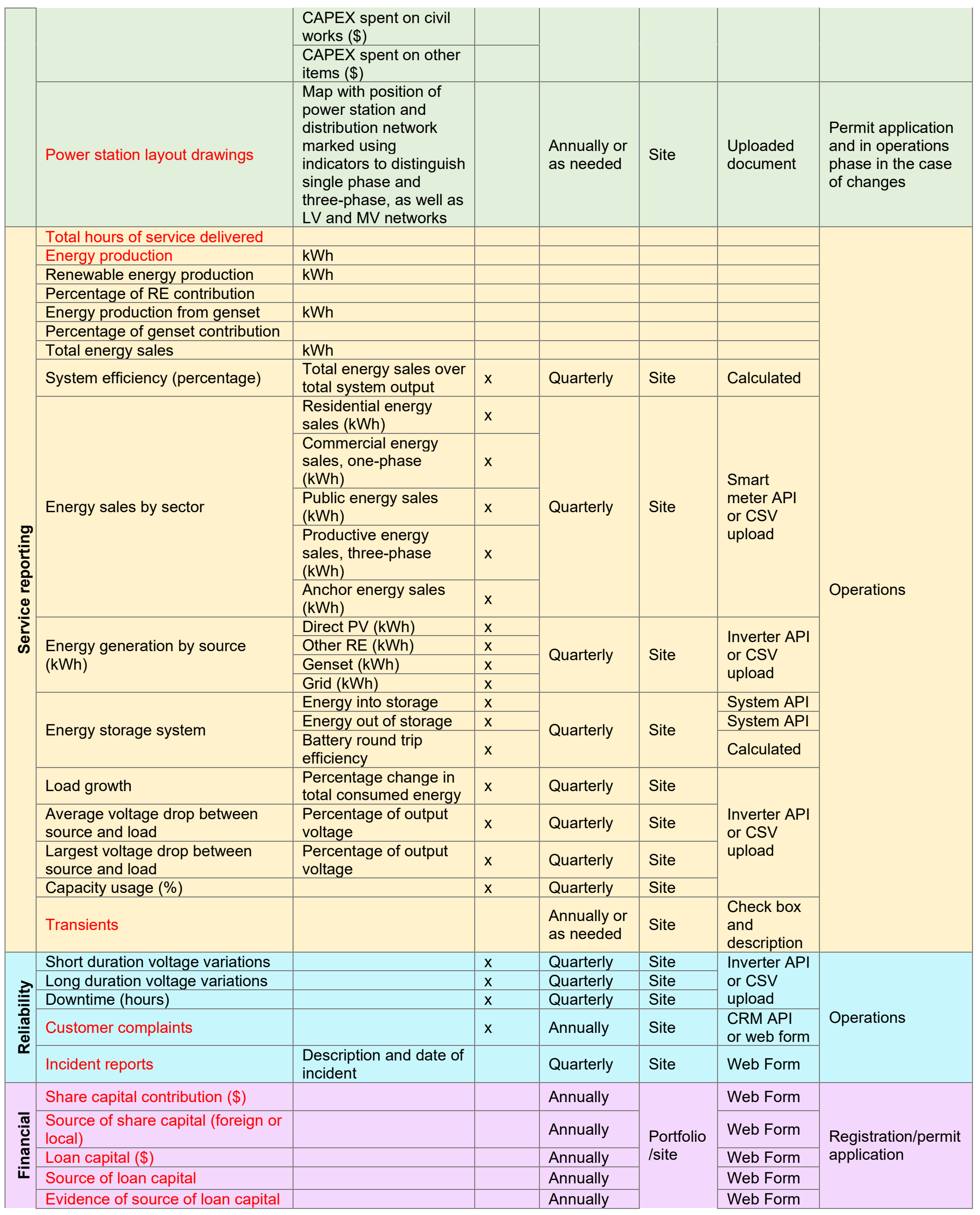




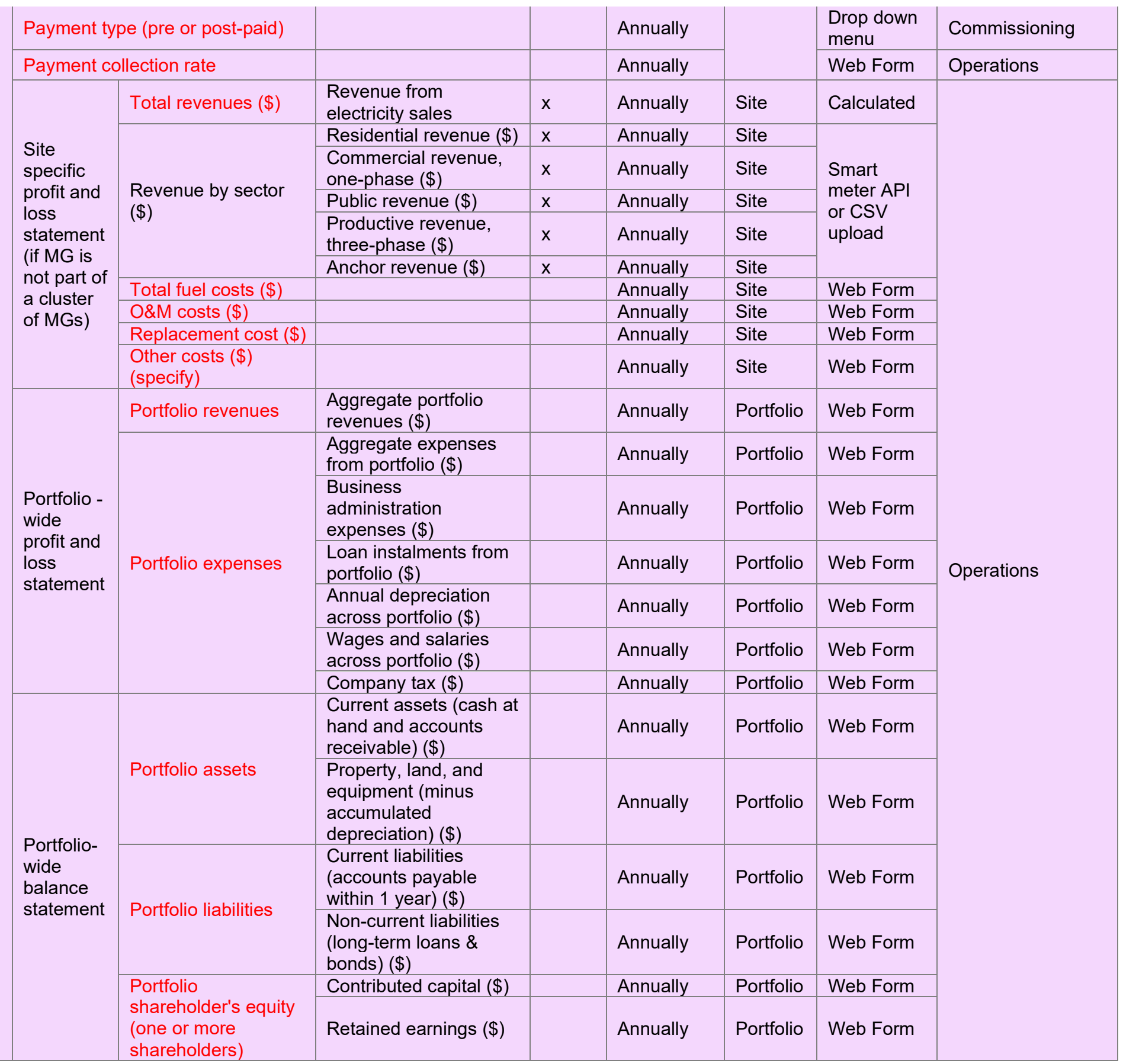




\section{Appendix C. SparkMeter Data Characteristics}

Table C- 1. Nominal Voltages, Number of Meters per Site, and Period of Data Availability

\section{SITE NUMBER NOMINAL VOLTAGE NUMBER OF METERS}

\section{START TIME}

$3 / 1 / 20170: 00$

$3 / 8 / 201717: 15$

$5 / 12 / 201716: 45$

11/1/2017 16:30

$5 / 1 / 20170: 00$

$12 / 1 / 20160: 00$

$230 \mathrm{~V} \quad 67$

$\begin{array}{llr}6 & 230 \mathrm{~V} & 67 \\ 7 & 230 \mathrm{~V} & 213\end{array}$

$8230 \mathrm{~V}$

$9230 \mathrm{~V}$

$10230 \mathrm{~V}$

$11230 \mathrm{~V}$

$12 \quad 230 \mathrm{~V}$

$13240 \mathrm{~V}$

$14240 \mathrm{~V}$

$15240 \mathrm{~V}$

$16240 \mathrm{~V}$

$17240 \mathrm{~V}$

$18240 \mathrm{~V}$

$19240 \mathrm{~V}$

$20 \quad 240 \mathrm{~V}$

$21240 \mathrm{~V}$

$22 \quad 230 \mathrm{~V}$

$23230 \mathrm{~V}$

$24230 \mathrm{~V}$

$25240 \mathrm{~V}$

$26230 \mathrm{~V}$

$27230 \mathrm{~V}$

$28 \quad 230 \mathrm{~V}$

$29 \quad 230 \mathrm{~V}$

$30 \quad 230 \mathrm{~V}$

$31 \quad 230$

$32 \quad 230 \mathrm{~V}$

$33230 \mathrm{~V}$

$34 \quad 230 \mathrm{~V}$

$35230 \mathrm{~V}$

36

213

$24 \quad 11 / 1 / 20170: 00$

$147 \quad 5 / 1 / 20160: 00$

$201 \quad 11 / 1 / 20160: 00$

$83 \quad 11 / 1 / 20160: 00$

$24 \quad 11 / 16 / 20170: 00$

$127 \quad 11 / 2 / 20170: 00$

$54 \quad 12 / 15 / 20170: 00$

$94 \quad 12 / 15 / 20170: 00$

$22112 / 15 / 20170: 00$

$11 / 15 / 20170: 00$

11/1/2017 18:15

12/15/2017 0:00

12/1/2017 0:00

12/4/2017 0:00

$6 / 15 / 20178: 30$

$11 / 15 / 20170: 00$

6/1/2017 0:00

4/1/2017 0:00

$11 / 1 / 20160: 00$

8/24/2017 16:45

7/6/2016 17:30

2/15/2017 12:15

11/1/2017 0:00

$4 / 15 / 20170: 00$

9/1/2017 0:00

$5 / 23 / 20170: 00$

$12 / 4 / 201715: 45$

8/15/2017 0:00

3/1/2017 0:00

\section{END TIME}

3/1/2018 18:30

$3 / 16 / 201815: 15$

3/17/2018 7:45

6/14/2018 23:45 $4 / 30 / 2018$ 23:45

$11 / 30 / 201723: 45$

6/13/2018 23:45

$6 / 14 / 201823: 45$

$4 / 30 / 2018$ 23:45

$5 / 31 / 201823: 45$

$5 / 31 / 201823: 45$

$5 / 10 / 201823: 45$

$6 / 14 / 201823: 45$

$6 / 14 / 2018$ 23:45

6/14/2018 23:45

6/14/2018 23:45

6/14/2018 23:45

6/14/2018 23:45

6/29/2018 23:45

$5 / 10 / 201823: 45$

6/29/2018 23:45

6/14/2018 19:15

6/14/2018 23:45

6/14/2018 23:45

$6 / 14 / 201823: 45$

11/29/2017 23:45

6/29/2018 23:45

8/24/2017 23:45

6/29/2018 23:45

6/29/2018 23:45

6/29/2018 23:45

6/29/2018 23:45

6/14/2018 23:45

6/14/2018 23:45

6/14/2018 23:45

5/31/2018 23:45

Note: The period of data availability listed here is based on the earliest and latest meter recording at each site. Individual meters may not have data covering the full period. 
Table C- 2. Descriptions of the Full Set of Data Parameters Provided by SparkMeter

\begin{tabular}{|c|c|c|}
\hline MEASUREMENT & UNIT & DESCRIPTION \\
\hline Minimum voltage & V & $\begin{array}{l}\text { Minimum voltage recorded over a } 100 \mathrm{~ms} \text { period at the end of } \\
\text { each 15-minute measurement period }\end{array}$ \\
\hline Maximum voltage & V & $\begin{array}{l}\text { Maximum voltage recorded over a } 100 \mathrm{~ms} \text { period at the end } \\
\text { of each } 15 \text {-minute measurement period }\end{array}$ \\
\hline Average voltage & V & $\begin{array}{l}\text { Average voltage recorded over each 15-minute measurement } \\
\text { period }\end{array}$ \\
\hline Minimum current & A & $\begin{array}{l}\text { Minimum current recorded over a } 100 \mathrm{~ms} \text { period at the end of } \\
\text { each 15-minute measurement period }\end{array}$ \\
\hline Maximum current & A & $\begin{array}{l}\text { Maximum current recorded over a } 100 \mathrm{~ms} \text { period at the end } \\
\text { of each 15-minute measurement period }\end{array}$ \\
\hline Average current & A & $\begin{array}{l}\text { Average current recorded over each 15-minute measurement } \\
\text { period }\end{array}$ \\
\hline Frequency & $\mathrm{Hz}$ & $\begin{array}{l}\text { Frequency recorded at the end of each } 15 \text {-minute } \\
\text { measurement period }\end{array}$ \\
\hline Power factor & - & $\begin{array}{l}\text { Average power factor over each 15-minute measurement } \\
\text { period }\end{array}$ \\
\hline Average active power & W & $\begin{array}{l}\text { Average active power recorded over each 15-minute } \\
\text { measurement period }\end{array}$ \\
\hline Instantaneous active power & W & $\begin{array}{l}\text { Instantaneous active power recorded at the end of each 15- } \\
\text { minute measurement period }\end{array}$ \\
\hline Average apparent power & VA & $\begin{array}{l}\text { Average apparent power recorded over each 15-minute } \\
\text { measurement period }\end{array}$ \\
\hline Energy consumption & kWh & Energy consumed since the last recording \\
\hline Electricity cost & $\$ / k W h$ & Cost of electricity \\
\hline Power limit & W & $\begin{array}{l}\text { Operator defined power limit over each 15-minute } \\
\text { measurement period }\end{array}$ \\
\hline Meter information & - & For example, meter ID, state, uptime \\
\hline
\end{tabular}




\section{usaid.gov/powerafrica | nrel.gov/usaid-partnership}

David Stonehill

Beyond the Grid Lead

USAID | Power Africa

Tel: +27 12-452-2086

Email: dstonehill@usaid.gov

\section{Eric Lockhart}

Project Leader

National Renewable Energy Laboratory (NREL)

Tel: +1-303-275-4637

Email: eric.lockhart@nrel.gov
The Power Africa, USAID, and NREL Partnership addresses critical challenges to scaling up the implementation and investment in micro-grids for energy access through technical support partnerships and application of NREL's Quality Assurance Framework.

The USAID-NREL Partnership addresses critical challenges to scaling up advanced energy systems through global technical platforms including Greening the Grid, Renewable Energy (RE) Data Explorer, and the International Jobs and Economic Development Impacts (I-JEDI) tool. More information can be found on each of these websites.

\section{USAID RNREL}

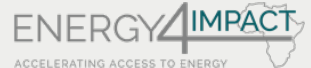

POWER

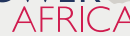

